\title{
CarbonTracker- $\mathrm{CH}_{4}$ : an assimilation system for estimating emissions of atmospheric methane
}

\author{
L. Bruhwiler ${ }^{1}$, E. Dlugokencky ${ }^{1}$, K. Masarie ${ }^{1}$, M. Ishizawa ${ }^{2}$, A. Andrews ${ }^{1}$, J. Miller ${ }^{1,4}$, C. Sweeney ${ }^{1,4}$, P. Tans ${ }^{1}$, and \\ D. Worthy ${ }^{3}$ \\ ${ }^{1}$ NOAA Earth System Research Laboratory, Global Monitoring Division, Boulder Colorado, USA \\ ${ }^{2}$ National Institute for Environmental Studies, Center for Global Environmental Research, Tsukuba, Japan \\ ${ }^{3}$ Environment Canada, Climate Research Division, Toronto, Ontario, Canada \\ ${ }^{4}$ Cooperative Institute for Research in Environmental Sciences, University of Colorado, Boulder, Colorado, USA
}

Correspondence to: L. M. Bruhwiler (lori.bruhwiler@noaa.gov)

Received: 18 October 2013 - Published in Atmos. Chem. Phys. Discuss.: 24 January 2014

Revised: 22 June 2014 - Accepted: 23 June 2014 - Published: 19 August 2014

\begin{abstract}
We describe an assimilation system for atmospheric methane $\left(\mathrm{CH}_{4}\right)$, CarbonTracker- $\mathrm{CH}_{4}$, and demonstrate the diagnostic value of global or zonally averaged $\mathrm{CH}_{4}$ abundances for evaluating the results. We show that CarbonTracker- $\mathrm{CH}_{4}$ is able to simulate the observed zonal average mole fractions and capture inter-annual variability in emissions quite well at high northern latitudes $\left(53-90^{\circ} \mathrm{N}\right)$. In contrast, CarbonTracker- $\mathrm{CH}_{4}$ is less successful in the tropics where there are few observations and therefore misses significant variability and is more influenced by prior flux estimates. CarbonTracker- $\mathrm{CH}_{4}$ estimates of total fluxes at high northern latitudes are about $81 \pm 7 \mathrm{Tg} \mathrm{CH}_{4} \mathrm{yr}^{-1}$, about $12 \mathrm{Tg} \mathrm{CH}_{4} \mathrm{yr}^{-1}$ (13\%) lower than prior estimates, a result that is consistent with other atmospheric inversions. Emissions from European wetlands are decreased by $30 \%$, a result consistent with previous work by Bergamaschi et al. (2005); however, unlike their results, emissions from wetlands in boreal Eurasia are increased relative to the prior estimate. Although CarbonTracker- $\mathrm{CH}_{4}$ does not estimate an increasing trend in emissions from high northern latitudes for 2000 through 2010, significant inter-annual variability in high northern latitude fluxes is recovered. Exceptionally warm growing season temperatures in the Arctic occurred in 2007, a year that was also anonymously wet. Estimated emissions from natural sources were greater than the decadal average by $4.4 \pm 3.8 \mathrm{Tg} \mathrm{CH}_{4} \mathrm{yr}^{-1}$ in 2007 .

CarbonTracker- $\mathrm{CH}_{4}$ estimates for temperate latitudes are only slightly increased over prior estimates, but about $10 \mathrm{Tg} \mathrm{CH}_{4} \mathrm{yr}^{-1}$ is redistributed from Asia to North America.
\end{abstract}

This difference exceeds the estimated uncertainty for North America $\left( \pm 3.5 \mathrm{Tg} \mathrm{CH}_{4} \mathrm{yr}^{-1}\right)$. We used time invariant prior flux estimates, so for the period from 2000 to 2006, when the growth rate of global atmospheric $\mathrm{CH}_{4}$ was very small, the assimilation does not produce increases in natural or anthropogenic emissions in contrast to bottom-up emission data sets. After 2006, when atmospheric $\mathrm{CH}_{4}$ began its recent increases, CarbonTracker- $\mathrm{CH}_{4}$ allocates some of the increases to anthropogenic emissions at temperate latitudes, and some to tropical wetland emissions. For temperate North America the prior flux increases by about $4 \mathrm{TgCH}_{4} \mathrm{yr}^{-1}$ during winter when biogenic emissions are small. Examination of the residuals at some North American observation sites suggests that increased gas and oil exploration may play a role since sites near fossil fuel production are particularly hard for the inversion to fit and the prior flux estimates at these sites are apparently lower and lower over time than what the atmospheric measurements imply.

The tropics are not currently well resolved by CarbonTracker- $\mathrm{CH}_{4}$ due to sparse observational coverage and a short assimilation window. However, there is a small uncertainty reduction and posterior emissions are about $18 \%$ higher than prior estimates. Most of this increase is allocated to tropical South America rather than being distributed among the global tropics. Our estimates for this source region are about $32 \pm 4 \mathrm{TgCH}_{4} \mathrm{yr}^{-1}$, in good agreement with the analysis of Melack et al. (2004) who obtained $29 \mathrm{Tg} \mathrm{CH}_{4} \mathrm{yr}^{-1}$ for the most productive region, the Amazon Basin. 


\section{Introduction}

Methane $\left(\mathrm{CH}_{4}\right)$ is second in importance to carbon dioxide $\left(\mathrm{CO}_{2}\right)$ among greenhouse gases with significant anthropogenic sources. It has a radiative forcing of, $0.5 \pm 0.05 \mathrm{Wm}^{-2}$, about $28 \%$ that of non- $\mathrm{CO}_{2}$ atmospheric constituents in 2010 (Hofmann et al., 2006; updated at http: //www.esrl.noaa.gov/gmd/aggi/). Over a $100 \mathrm{yr}$ time horizon $\mathrm{CH}_{4}$ is 28 times more efficient per mass as a greenhouse gas than $\mathrm{CO}_{2}$ (Myhre et al., 2013).

Global emissions of $\mathrm{CH}_{4}$ are between 500 and $600 \mathrm{Tg} \mathrm{CH}_{4} \mathrm{yr}^{-1}$ (Kirschke et al., 2013 and this work) and about $40 \%$ of this is due to natural sources, mainly wetlands. The other $60 \%$ of global emissions are due to microbial emissions associated with rice agriculture, livestock and waste, and fugitive emissions from fossil fuel production and use (Denman et al., 2007). Global emissions have recently been approximately in balance with global sinks, mainly chemical destruction by reaction with $\mathrm{OH}$, but also from oxidation by soil microbes, and atmospheric reactions with $\mathrm{O}^{1} \mathrm{D}$ and $\mathrm{Cl}$ in the stratosphere. The lifetime of $\mathrm{CH}_{4}$ in the atmosphere is about $10 \mathrm{yr}$ (e.g., Dlugokencky et al., 2003) with $\mathrm{CO}_{2}$ the eventual product of its oxidation.

$\mathrm{CH}_{4}$ has increased from a preindustrial abundance of $722 \pm 4 \mathrm{ppb}$ (Etheridge et al., 1998 after conversion to the NOAA $2004 \mathrm{CH}_{4}$ standard scale, Dlugokencky et al., 2005) to current values of about 1800 ppb in 2010 (about 2.5 times), and it is likely that human activity is responsible for most of this increase. Current levels are unprecedented over at least the last $800 \mathrm{kyr}$ (Loulerge et al., 2008). NOAA atmospheric network observations extend back to the 1980s, and show that global $\mathrm{CH}_{4}$ increased rapidly through the late 1990s, leveled off during the early 2000s and have recently begun to increase since 2007 (Rigby et al., 2008; Dlugokencky et al., 2009). The subject of the causes of the recent increase is the topic of much recent work (e.g., Bousquet et al., 2011), including this study.

An important aspect of atmospheric $\mathrm{CH}_{4}$ is the sensitivity of natural wetland emissions to climate change. Emissions from the Arctic, in particular, have the potential to increase significantly as temperatures rise and the vast stores of soil carbon thaw (e.g., Schuur et al., 2011; Harden et al., 2012). Schaefer et al. (2011) pointed out that potential carbon emissions from the Arctic could have important implications for policies aimed at reducing or stabilizing emissions. This clearly highlights the importance of maintaining longterm measurements of atmospheric $\mathrm{CH}_{4}$ in the Arctic, and in this study we hope to further the case for atmospheric inverse techniques as a tool to diagnose observed atmospheric records (see previous studies by Hein et al., 1997; Houweling et al., 1999, 2013; Chen and Prinn, 2006; Bergamaschi et al., 2005, 2014; Bousquet et al., 2006).

Atmospheric $\mathrm{CH}_{4}$ is also influenced by diverse human activities, ranging from food production (ruminants and rice) to waste (sewage and landfills) to fossil fuel production (coal, oil and gas). Future increases in population could increase emissions from agriculture and waste as demand for more food production rises, while the current boom in shale oil/gas exploitation has focused attention on leakage from drilling, storage and transport of fossil fuel (e.g., Pétron et al., 2012). An obvious use of an atmospheric assimilation system is to quantify changes in anthropogenic emissions and attribute increases at policy relevant spatial scales, something that is possible only with adequate spatial coverage of observations. In this study we will discuss the degree to which this is currently possible given the coverage of the current observational network.

The work we present here uses only surface observations rather than combinations of surface observations and retrievals space-based instruments as used by Bergamaschi et al. (2013) and Houweling et al. (2014). Our study differs from that of Bergamaschi et al. (2013) since they used a subset of 30 surface observations sampling mainly background marine air that existed over the entire decade, as well as satellite retrievals. In our study we have used most available surface observations, including those that are sensitive to terrestrial emissions (Table 2). We use the same transport model as Bergamaschi et al. (2013) and Houweling et al. (2014), however, we use a different assimilation technique and different strategies for weighting observations and priors. We also include a discussion of observationally derived quantities that useful evaluation of our results.

The next section is a detailed description of our $\mathrm{CH}_{4}$ assimilation system, CarbonTracker- $\mathrm{CH}_{4}$, followed by a detailed evaluation of its performance. In Sect. 4, we discuss results from CarbonTracker- $\mathrm{CH}_{4}$ for 2000-2010.

\section{The CarbonTracker ensemble data assimilation system}

The total emission of $\mathrm{CH}_{4}$ in time and space may be described by

$$
\begin{aligned}
& F(x, y, t)=\lambda_{1} \cdot F_{\text {natural }}(x, y, t)+\lambda_{2} \cdot F_{\text {fossil }}(x, y, t)+\lambda_{3} \\
& \quad \cdot F_{\text {agriculture }} / \text { waste } \\
& \quad \cdot(x, y, t)+\lambda_{4} \cdot F_{\text {fire }}(x, y, t)+\lambda_{5} \\
& \quad F_{\text {ocean }}(x, y, t),
\end{aligned}
$$

where $\lambda_{i}$ represents a set of linear scaling factors to be estimated in the assimilation that are applied to the fluxes $(F)$ by multiplying prior estimates of $\mathrm{CH}_{4}$ fluxes to produce the posterior flux estimates. The prior values of the scaling factors is 1 . A total of 121 parameters per week are estimated; 10 terrestrial emission processes for 12 continental regions (corresponding to the Transcom 3 continental regions (Gurney et al., 2000) but with the addition of a tropical African region, see http://transcom.project.asu.edu for a map, or Fig. 1), and fluxes from the global ocean. Each weekly assimilation step, emissions for the previous 5 weeks are estimated following the fixed lag Kalman smoother methodology described by Bruhwiler et al. (2005). The terrestrial emissions 


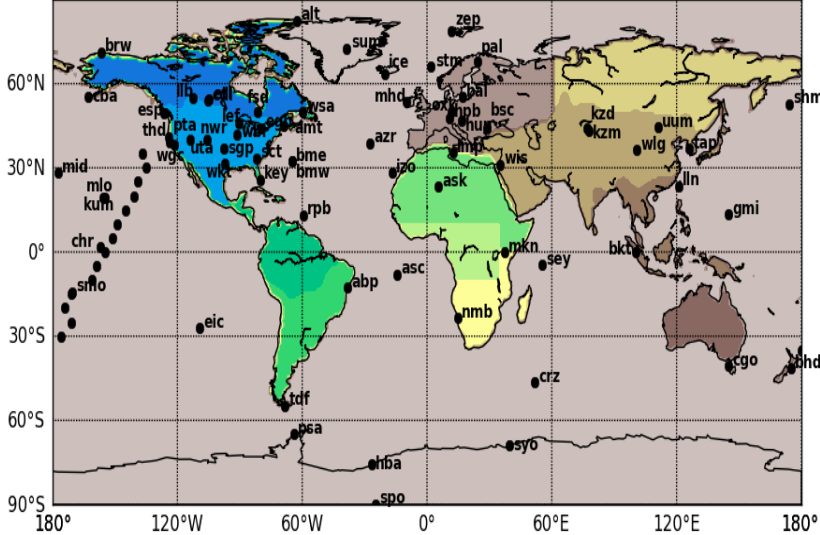

Figure 1. Map showing locations of observations used in CarbonTracker- $\mathrm{CH}_{4}$. Shading indicates the boundaries of the Transcom 3 source regions (Gurney et al., 2000) with an additional tropical African region.

include fugitive emissions from coal, oil and gas production (estimated as one source); agriculture and waste emissions (rice production, for example); livestock and their waste; and emissions from landfills and waste water. Natural emissions include contributions from wetlands, termites, uptake in soils and wild animals. The final terrestrial emission category is biomass burning, which is treated as a separate category due to the existence of strong spatial constraints coming from satellite observations of locations of large fires. In general, the spatial distribution of the prior flux estimates is an important constraint on the assimilation. For example, the known location of fossil fuel production from bottom-up emission data sets provides information pertaining to the assimilation system on whether a signal measured at a particular observation site could have a fossil fuel component. If production areas change over time and are not captured by the prior distribution, then fossil fuels will be underestimated by the inversion.

In this study we estimate emissions for continental scale source regions, and although we rely on the prior spatial distribution of the prior emissions to distribute the emissions, the use of large source regions can lead to aggregation errors as shown by Kaminski et al. (2001). An alternative would be to solve for many more sources, possibly at grid scale. However, without significantly more observational constraints, our solution would be very dependent on not only the prior emissions, but also their assumed spatial and temporal covariance. Ultimately, use of space-based observations might be the preferred solution. At present, significant issues with space-based emissions still exist, such as quantification of biases that vary with space and time (e.g., Houweling et al., 2013). On the other hand, as discussed by Bruhwiler et al. (2011), the global network can constrain certain aspects of the budgets of greenhouse gases, even with its bias towards background atmospheric sites.
We initialized the assimilation using an equilibrated distribution produced by a previous TM5 run that was scaled to match observed zonal average $\mathrm{CH}_{4}$ mixing ratio for the year 2000. The north-south gradient therefore should represent the observed atmospheric gradient at the surface. Sensitivity runs using synthetic data (not shown) suggest that spin-up effects are restricted to within in the first half year of the assimilation.

\subsection{Ensemble size and localization}

The ensemble Kalman smoother system used to solve for the scalar multiplication factors is based on that described by Peters et al. (2005), and uses the square root ensemble Kalman filter of Whitaker and Hamill (2002). The length of the smoother window is restricted to 5 weeks for computational efficiency. Although the posterior flux estimates in relatively densely sampled regions such as North America were found to be robust by Peters et al. (2005) with a window this short, regions with less dense observational coverage (the tropics, for example) are likely to be poorly constrained even after more than a month of transport and therefore not well resolved. As pointed out by Bruhwiler et al. (2005), a smoother window of at least 3 months is likely to make maximal use of remote network sites, however this may come at the expense of accumulated errors in transport as claimed by Peters et al. (2007). The extent to which this is true is a subject for further study. Even without the problem of a short smoother window, the sparseness of the observational network makes it difficult to resolve under-sampled regions such as the tropical terrestrial biosphere (Bruhwiler et al., 2011).

Statistics for the ensemble are created from 500 members using the prior covariance matrix of the parameters, each with its own background $\mathrm{CH}_{4}$ concentration field to represent the time history (and thus covariances) of the filter. We experimented with different numbers of ensemble members and found that the use of too few ensemble members results in solutions that stay artificially close to prior flux estimates. To dampen spurious noise due to the approximation of the covariance matrix, we apply localization (Houtekamer and Mitchell, 1998) for non-background sites. By limiting correlations between distant sites, localization ensures that random correlations between parameters do not translate into unrealistic constraints on emissions by distant measurement sites (i.e., those connections physically impossible with only 5 weeks of transport). Following Peters et al. (2005) localization is based on the linear correlation coefficient between the 500-parameter deviations and 500 observation deviations for each parameter, with a cut-off at $95 \%$ significance in a student's $t$ test with a two-tailed probability distribution.

As noted above, the posterior covariance matrix is approximated by using the posterior parameter deviations. Temporal covariance is limited to the period spanned by the assimilation window. Therefore, time aggregated quantities, such 
as annual uncertainties will likely be overestimates since information about temporal covariations will be limited. Furthermore, as with any inversion, the error covariance matrix ultimately reflects the relative weighting between the modeldata mismatch errors and prior emission uncertainties that are specified.

\subsection{Covariance structure}

In our assimilation, the chosen 1-s error of the prior estimates is $75 \%$ for all parameters. The prior covariance structure describes the uncertainty on each parameter, plus their correlation in space. For the current version of CarbonTracker- $\mathrm{CH}_{4}$, we assumed a diagonal prior covariance matrix so that no prior correlations between estimated parameters exist. The effect of this choice may be strong anti-correlations among estimated parameters in regions where few observational constraints exist; however, larger-scale aggregations of these regions are expected to yield more robust estimates. For example, the total tropical source can be better determined that the individual regions between which there can be trade-offs in emissions from time step to time step. Note also that the 5-week assimilation window used by CarbonTracker limits knowledge of temporal correlations. As a result, the uncertainty on annual average emissions is difficult to estimate.

\subsection{TM5 atmospheric transport model}

Transport Model 5 (TM5, Krol et al., 2005) is a community supported global model with two-way nested grids. For CarbonTracker- $\mathrm{CH}_{4}$, we ran the simulation at $4^{\circ}$ latitude $\times$ $6^{\circ}$ longitude resolution without zoom regions. TM5 is developed and maintained jointly by the Institute for Marine and Atmospheric Research Utrecht (IMAU, the Netherlands), the Joint Research Centre (JRC, Italy), the Royal Netherlands Meteorological Institute (KNMI, the Netherlands), and the National Oceanic \& Atmospheric Administration (NOAA) Earth System Research Laboratory (ESRL, USA). TM5 has detailed treatments of advection, convection (deep and shallow), and vertical diffusion in the planetary boundary layer and free troposphere. The winds used for transport in TM5 come from the European Center for Medium range Weather Forecast (ECMWF) operational forecast model. This "parent" model currently runs with $\sim 25 \mathrm{~km}$ horizontal resolution and 60 layers in the vertical prior to 2006 and 91 layers in the vertical from 2006 onwards.

The ECMWF meteorological data are preprocessed into coarser grids and are converted from wind fields to mass conserving horizontal and vertical mass fluxes. TM5 runs at an external time step of 3 hours, but due to the symmetrical operator splitting between advection, diffusion, emissions and loss the effective time step over which each process is applied is shorter. The vertical resolution of TM5 used with CarbonTracker- $\mathrm{CH}_{4}$ is 34 hybrid sigma-pressure levels (from 2006 onwards; 25 levels for 2000-2005), unevenly spaced with more levels near the surface. At the time the calculations discussed in this study were done, we did not have the ERA-Interim reanalysis driving meteorology and older reanalyses did not cover the time span we were interested in. Comparisons of forward simulations suggest that differences between ERA-I and OD for $\mathrm{CH}_{4}$ at surface sites is very small, both before and after the change in the vertical levels. Assimilations run with both data products for CarbonTracker $\left(\mathrm{CO}_{2}\right)$ produce virtually indistinguishable results in estimated fluxes (see http://www.esrl.noaa.gov/gmd/ccgg/carbontracker/).

As noted by Peters et al. (2004), TM5 overestimates the meridional gradient of $\mathrm{SF}_{6}$ by about $20 \%$. A systematic comparison of a suite of transport models described by Denning et al. (1999) found that some transport models appear to underestimate mixing processes, especially near the surface, while others mix emissions more rapidly throughout the lower atmosphere. They also found that models that underestimate mixing produce relatively good simulations of marine boundary layer sites while overestimating concentrations at continental sites. More diffusive models produced worse marine boundary layer simulations, but did better for continental sites. TM5 falls into less-diffusive category, but current ongoing development is aimed at improving the situation. It must be acknowledged that the emissions estimates in our study may be biased due to inadequate vertical mixing. For example, more vertical mixing will diffuse emissions throughout a deeper atmospheric column, and this may result in higher emissions in order to match observations.

\subsection{Prior emission estimates for natural sources}

The largest natural emissions of methane are from wetlands, defined as regions that are permanently or seasonally water logged. Wetlands are a broad category that includes both high-latitude bogs and fens and tropical swamps. Saturated soils in warm tropical environments tend to produce the most methane. However, warming Arctic temperatures raise concerns of increasing output from high-latitude wetlands and future decomposition of carbon currently stored in frozen Arctic soils (e.g., Schaefer et al., 2011).

Methane is rapidly oxidized by methanotrophic bacteria in overlying aerobic water columns or unsaturated soil, so the water table must be at or near the surface and the depth of overlying water must be shallow for large emissions to occur. Wetland plants have adapted to low oxygen environments by having hollow stems to allow delivery of oxygen and other gases to root systems. These hollow stems also allow delivery of methane directly to the atmosphere, and along with ebullition account for most of transport to the atmosphere. Diffusion also occurs but is a significantly smaller contribution to the atmosphere. (See Barlett and Harris (1993) for an extensive overview of wetland emissions.) Bottom-up estimates of global emissions from wetlands are about 150 $200 \mathrm{Tg} \mathrm{CH}_{4} \mathrm{yr}^{-1}$ with most of this occurring in tropical regions (Melton et al., 2013). Because emissions are sensitive 
to temperature and precipitation, they exhibit significant seasonal cycles, especially at high latitudes, as well as interannual variability due to moisture and temperature variability.

Methane emissions from wetlands are difficult to quantify using assimilation systems for two reasons; their global spatial distribution is difficult to know accurately, and there is large variability in emission rates over small spatial scales (meters), which makes extrapolation to large scales difficult. Here we used the prior flux estimates of Bergamaschi et al. (2005) that are based on the wetland distribution of Matthews (1989) and the wetland emission model of Kaplan (2002) that parameterizes emissions based on moisture, temperature and soil carbon. The global total of the prior flux estimate is $175 \mathrm{TgCH}_{4} \mathrm{yr}^{-1}$.

Other natural sources of methane include enteric fermentation in insects (mainly termites, Sanderson, 1996) and wild ruminants (Houweling et al., 1999). Prior values for both of these sources $\left(\sim 25 \mathrm{Tg} \mathrm{CH}_{4} \mathrm{yr}^{-1}\right)$ are much smaller than the wetland source. Oxidation of $\mathrm{CH}_{4}$ in dry soils ( $\sim 40 \mathrm{Tg} \mathrm{CH}_{4} \mathrm{yr}^{-1}$, Ridgwell et al., 1999) is a natural sink of $\mathrm{CH}_{4}$ and is treated as a negative source in the assimilation.

\subsection{Prior emission estimates for fugitive emissions from fossil fuels}

Methane is the principal component of natural gas, and leaks to the atmosphere associated with natural gas production and distribution are a considerable source. Natural gas is associated with oil production and is often flared, or simply vented to the atmosphere. Together, anthropogenic emissions from oil and gas production are thought to contribute about $50 \mathrm{Tg} \mathrm{CH}_{4} \mathrm{yr}^{-1}$ ( $\sim 10 \%$ of the global annual methane emissions, EDGAR 3.2FT2000 (European Commission, JRC, 2009). Methane is also associated with coal deposits and can be released by extracting and pulverizing coal. It is often vented directly to the atmosphere from mines, and this source contributes an additional $\sim 20 \mathrm{Tg} \mathrm{CH}_{4} \mathrm{yr}^{-1}$ (EDGAR 3.2FT2000 (European Commission, JRC, 2009). As Asian economies have undergone rapid growth, coal production there has increased by a factor of about two since 2000, while remaining approximately level for most of the rest of the world. In 2010, production of coal by China increased by $9 \%$ over the previous year (BP Statistical Energy Review, 2011).

Combustion of natural gas is currently used to generate about a quarter of the electricity produced in the US. Its popularity as a fuel has recently grown because it is a relatively clean and efficient source of energy. Recent technological advances in recovery of natural gas, principally hydraulic fracturing, have led to increases in reserve estimates, and a tremendous increase in exploitation of shale oil/gas deposits in North America (e.g., Energy Information Administration; http://www.eia.gov). It is possible that as natural gas reserves are increasingly exploited, emissions related to its production and distribution will rise in the future.
CarbonTracker- $\mathrm{CH}_{4}$ uses the $1^{\circ} \times 1^{\circ}$ gridded emissions from EDGAR 3.2FT2000 (European Commission, JRC, 2009) as prior emission estimates for fugitive emissions from coal, oil and gas production. This data set is based on emission inventories by country and sector for 1990 and 1995 extrapolated to 2000 using production and consumption statistics. We have not extrapolated this data over the period covered by CarbonTracker- $\mathrm{CH}_{4}$, and have instead kept prior emission estimates constant at 2000 levels. This will allow us to test whether the emission estimates suggest changes in anthropogenic emissions, for example, the large increase in emissions from coal production in Asia or the significant increase in oil and gas drilling over the last decade in North America. In some cases, the spatial distributions of priors may not be accurate since they may be based on simple assumptions like population. For other emissions, there may have been changes in the spatial distribution of emissions over the decade, oil and gas drilling in North America for example. The atmospheric inversions allow the possibility of diagnosing these problems in the underlying prior emission data sets and may lead to improvements in methodology.

\subsection{Prior emission estimates for agriculture and waste}

The largest source of methane emitted by human activity is agriculture and waste; emissions from rice agriculture, waste/wastewater, and animals and their waste total 230$250 \mathrm{Tg} \mathrm{CH}_{4} \mathrm{yr}^{-1}$. Ruminants, such as cattle, goats, sheep and water buffalo are able to convert hard-to-digest forage to energy through enteric fermentation, in which microbes produce easily digested material inside the animal's gut. Emissions from enteric fermentation may be expected to increase with increasing human population and higher standards of living. Animal waste, along with waste water and landfills produce $\mathrm{CH}_{4}$ when conditions favor anaerobic decomposition. Organic material is decomposed in low oxygen conditions by chains of microbial processes that terminate in production of methane by methanogens.

Rice agriculture is also a significant source of methane to the atmosphere. This is because warm, waterlogged organicrich soils in rice paddies are ideal for methanogenesis. Bottom-up estimates of emissions from rice agriculture are $50 \mathrm{Tg} \mathrm{CH}_{4} \mathrm{yr}^{-1}$, and emissions can be significantly reduced by drainage of paddies between harvests as well as other agricultural practices (Yan et al., 2009).

CarbonTracker- $\mathrm{CH}_{4}$ uses the $1^{\circ} \times 1^{\circ}$ gridded emissions from the EDGAR 3.2FT2000 as prior emission estimates for enteric fermentation, animal waste management, waste water and landfills. This data set is based on emission inventories by country and sector for the years 1990 and 1995 extrapolated to 2000 using production and consumption statistics. For rice agriculture, we used the seasonally varying emissions of Matthews et al. (1991). We have not extrapolated this data over the period covered by CarbonTracker- $\mathrm{CH}_{4}$, and 
have instead kept prior emission estimates constant at 2000 levels as for fossil fuel emissions.

\subsection{Prior emission estimates for biomass burning}

Fires are a relatively small part of the atmospheric $\mathrm{CH}_{4}$ budget: $15-20 \mathrm{Tg} \mathrm{CH}_{4} \mathrm{yr}^{-1}$ out of a total of $\sim 520 \mathrm{Tg} \mathrm{CH}_{4} \mathrm{yr}^{-1}$, however, they are an important contribution to inter-annual variability of methane.

The fire prior currently used in CarbonTracker- $\mathrm{CH}_{4}$ is based on the Global Fire Emissions Database (GFED), which uses the CASA (Carnegie-Ames-Stanford Approach) biogeochemical model to estimate the carbon fuel in various biomass pools along with burned area based on MODIS satellite observations of fire counts (Giglio et al., 2006; van der Werf et al., 2006). The data set consists of $1^{\circ} \times 1^{\circ}$ gridded monthly burned area, fuel loads, combustion completeness, and fire emissions for numerous atmospheric constituents, including $\mathrm{CH}_{4}$ for the time period spanning January 1997-December 2010.

\subsection{Prior estimates for ocean fluxes}

The oceans play a relatively small role in the budget of atmospheric methane, contributing only $\sim 2-3 \%$ of global emissions $\left(\sim 10-15 \mathrm{Tg} \mathrm{CH}_{4} \mathrm{yr}^{-1}\right)$. A significant fraction of this is assumed to come from methane seeps in shallow coastal waters $\left(\sim 5 \mathrm{Tg} \mathrm{CH}_{4} \mathrm{yr}^{-1}\right)$. The overlying water column must be shallow for emission to the atmosphere, since $\mathrm{CH}_{4}$ is efficiently consumed by aerobic microbial processes. The water column also needs to be shallow for bubbles to deliver methane directly to the air. Coastal waters are sometimes supersaturated in $\mathrm{CH}_{4}$, and may emit about $6 \mathrm{Tg} \mathrm{CH}_{4} \mathrm{yr}^{-1}$ to the atmosphere, while the open may add another $3 \mathrm{Tg} \mathrm{CH}_{4} \mathrm{yr}^{-1}$ (Houweling et al., 1999; Lambert and Schmidt, 1993).

Rhee et al. (2009) have suggested that global ocean emissions excluding natural seeps is much smaller than the $\sim 9 \mathrm{TgCH}_{4} \mathrm{yr}^{-1}$ we have used in this version of CarbonTracker- $\mathrm{CH}_{4}$, only about $0.6-1.2 \mathrm{Tg} \mathrm{CH}_{4} \mathrm{yr}^{-1}$. On the other hand, recent studies conducted in the coastal waters of the eastern Siberian Arctic hint at the possibility of a significant source of methane coming from methane bubbling from the continental shelf sediments (Shakhova et al., 2010). For this version of CarbonTracker- $\mathrm{CH}_{4}$ we followed the approach of Bergamaschi et al. (2009) and used the estimates of Houweling et al., (1999) and Lambert and Schmidt (1993) as prior flux estimates. We also assumed an uncertainty on these prior flux estimates of $\pm 75 \%$.

\subsection{Atmospheric chemical loss}

Methane is removed from the atmosphere mainly by reaction with hydroxyl radical $(\mathrm{OH})$, but also by reaction with atomic chlorine $(\mathrm{Cl})$ and excited-state oxygen $\left(\mathrm{O}^{1} \mathrm{D}\right)$ in the stratosphere. The chemical loss of methane over a year is about equal to the total input from sources $\left(\sim 520 \mathrm{Tg} \mathrm{CH}_{4} \mathrm{yr}^{-1}\right)$, and the mean lifetime of methane is $9-10 \mathrm{yr}$. Small differences in the emissions and losses lead to trends in atmospheric $\mathrm{CH}_{4}$ abundance, while year to year changes in the balance of emissions and loss lead to inter-annual variability and possibly to trends in observed methane.

Hydroxyl radical is extremely reactive and has such a short atmospheric residence time that it is difficult to directly measure its global distribution. Instead, observations of atmospheric species that have relatively well-quantified anthropogenic emissions and are destroyed only by reaction with $\mathrm{OH}$, such as methyl chloroform $\left(\mathrm{CH}_{3} \mathrm{CCl}_{3}\right)$, are used, often along with atmospheric models, to estimate the abundance of atmospheric $\mathrm{OH}$. Using an empirical approach, Montzka et al. (2011) noted that the inter-annual variability in atmospheric $\mathrm{OH}$ is likely to be within about $\sim 2 \%$. Errors in derived $\mathrm{OH}$ distributions arise from uncertainty in the emissions of $\mathrm{CH}_{3} \mathrm{CCl}_{3}$ used to estimate $\mathrm{OH}$ and uncertainties in transport models. Krol et al. (1998) estimated that the uncertainty in globally averaged $\mathrm{OH}$ is $\pm 10 \%$.

About $10 \%$ of total chemical loss is due to transport and chemical destruction in the stratosphere. A small amount of this methane-depleted air is returned to the troposphere and could influence interpretation of high-altitude (aircraft) measurements of methane. In addition, errors in simulating stratosphere-troposphere transport could result in biases for model simulations covering many years.

Errors in the chemical loss of methane and the inability to adequately resolve inter-annual variability of $\mathrm{OH}$ are troublesome for estimation of methane fluxes. A $2 \%$ variation in the global methane sink is equivalent to $\sim 10 \mathrm{Tg} \mathrm{CH}_{4} \mathrm{yr}^{-1}$, about the size of estimated inter-annual variability in methane emissions.

For the present version of CarbonTracker- $\mathrm{CH}_{4}$ we use pre-calculated $\mathrm{OH}$ fields from a full-chemistry TM5 simulation that have been optimized against global observations of methyl chloroform. The chemical loss fields consist of a single, repeating seasonal cycle, and result in a methane lifetime of about $9.5 \mathrm{yr}$. Details of the chemical loss fields may be found in Bergamaschi et al. (2005).

\subsection{Observational constraints}

This study uses measurements of air samples collected at surface sites in the NOAA ESRL Cooperative Global Air Sampling Network (http://www.esrl.noaa.gov/gmd/ccgg/ flask.html) except those identified as having analysis or sampling problems, or those thought to be strongly influenced by local sources. The availability of data varies over time. Data collection, quality control and analysis methods are described in detail by Dlugokencky et al. (1994). A map of sites used in CarbonTracker- $\mathrm{CH}_{4}$ is shown in Fig. 1. In addition, we use in situ quasi-continuous $\mathrm{CH}_{4}$ time series from the following towers operated by Environment Canada (EC): $30 \mathrm{~m}$ above ground level (a.g.l.) at Candle Lake (CDL, 
Table 1. CarbonTracker- $\mathrm{CH}_{4}$ data preprocessing.

\begin{tabular}{ll}
\hline $\begin{array}{l}\text { Measurement } \\
\text { Program }\end{array}$ & Data Preprocessing \\
\hline $\begin{array}{l}\text { ESRL discrete } \\
\text { surface }\end{array}$ & $\begin{array}{l}\text { All valid* data. Multiple values from } \\
\text { the same day and location are averaged. } \\
\text { No sample time-of-day restriction (see } \\
\text { exception below). }\end{array}$ \\
\hline EC in situ sites & $\begin{array}{l}\text { All valid data from highest intake. Day } \\
\text { average using 12-16 LST. }\end{array}$ \\
\hline
\end{tabular}

* In this context "Valid Data" means the observation is thought to be free of sampling and analytical problems and has not been influenced by local sources.

formerly Old Black Spruce), SK, Canada, 105 m a.g.1. at East Trout Lake, SK, Canada (ETL), $40 \mathrm{~m}$ a.g.l. at Fraserdale, ON, Canada (FRD), and $10 \mathrm{~m}$ a.g.1. at Lac Labiche, AB, Canada (LLB). Other in situ quasi-continuous $\mathrm{CH}_{4}$ time series used are from the EC Canadian sites at Alert, Nunavut (ALT), Sable Island, NS (SBL) and Egbert, ON (EGB). All observations used in CarbonTracker- $\mathrm{CH}_{4}$ are calibrated against the WMO GAW (World Meteorological Organization, Global Atmosphere Watch) $\mathrm{CH}_{4} \mathrm{X} 2004$ mole fraction scale (Dlugokencky et al., 2005).

For most quasi-continuous sampling sites, we construct an afternoon daytime average mole fraction for each day from the time series, recognizing that our atmospheric transport model does not always capture the continental nighttime stability regime while daytime well-mixed conditions are better matched. Table 1 summarizes how data from the different measurement programs are preprocessed for this study.

We further exclude non-marine boundary layer (MBL) observations that are very poorly forecasted in our framework following the strategy used with CarbonTracker- $\mathrm{CO}_{2}$. We use the so-called model-data mismatch in this process, a quantity that represents random error ascribed to each observation to account for measurement and modeling errors at each site. If the observed-minus-forecasted mole fraction exceeds 3 times the prescribed mismatch, then the observation is not used at that time-step of the inversion. This can happen when an air sample influenced by local emissions is not captured well by our $1^{\circ} \times 1^{\circ}$ fluxes, or when local meteorological conditions are not captured by our offline transport fields. A complete list of sites used in CarbonTracker- $\mathrm{CH}_{4}$ is given in Table 2, along with the model-data mismatch used, the number of points available, the number that were excluded, and statistics on the posterior fit to each site.

Model-data mismatches were determined by assigning each site to a particular category; marine boundary layer (7.5 ppb), terrestrial (30 pbb), mixed marine and terrestrial (15 or $25 \mathrm{ppb}$ ), tower (25 or $30 \mathrm{ppb)} \mathrm{and} \mathrm{hard} \mathrm{to} \mathrm{fit} \mathrm{sites}$ (75 ppb). The model-data mismatch values were based on evaluation of forward runs and experience gained from CarbonTracker $\left(\mathrm{CO}_{2}\right.$, Peters et al., 2005). We forced the assimi- lation to closely match remote marine background sites while some sites were given a very large model-data mismatch because they are likely influenced by strong local sources. A complete list of sites and their model-data mismatches is shown in Table 2.

\section{Evaluation of CarbonTracker- $\mathrm{CH}_{4}$}

In this section we discuss the evaluation of CarbonTracker$\mathrm{CH}_{4}$ using three methods: comparison of prior and posterior residuals (difference between simulated and observed $\mathrm{CH}_{4}$ concentration), comparisons to profiles measured from aircraft that were not used in the assimilation, and comparisons to integrated global and zonal concentration and growth rate.

\subsection{Residuals}

The prior and posterior residuals, calculated by subtracting the observed $\mathrm{CH}_{4}$ mole fraction at each site constraining the inversion from the simulated prior or posterior abundances, are shown in Fig. 2. The bottom panel shows that the balance between the prior emissions and the chemical sink leads to an underestimate of $\mathrm{CH}_{4}$ relative to observations at all latitudes. By the end of the simulation, the negative bias of the model using prior fluxes reaches values up to $75 \mathrm{ppb}$ (compared to a global average of $\sim 1790 \mathrm{ppb}$ in 2009 , about $4 \%$ ). This negative bias is considerably reduced for the posterior residuals, as is shown in the top panel, and at most sites the posterior residuals are within $\sim 15 \mathrm{ppb}$ of the observations. This is partly by design, since the model-data mismatch determines how closely the posterior $\mathrm{CH}_{4}$ abundances must match the observations; however, as Table 1 shows, the posterior residuals even for some sites that have large modeldata mismatch error assigned to them, can be quite small. An example is BKT (Bukit Kototabang, Indonesia), with a model-data mismatch of $75 \mathrm{ppb}$ and a posterior residual of only $6.8 \mathrm{ppb}$. For sites like this, future inversions could use reduced model-data mismatch errors, allowing the observations to more strongly constrain the inversion.

Figure 2 shows that even after assimilation of observations, some sites have large low biases (implying emissions higher than prior estimates are needed to match the observations) and Fig. 3 shows the relative sizes of the residuals. WGC (Walnut Grove, CA is located in near a densely populated urban area and agriculture and has an average posterior residual of $-118 \mathrm{ppb}$. In addition to the difficulty of using relatively coarse resolution global transport to simulate observations amidst strong local sources, it is also likely that the prior emissions are underestimated. Other sites with large biases are WKT (central Texas) and SGP (Southern Great Plains, OK) with average residuals of $-49 \mathrm{ppb}$ and $-57 \mathrm{ppb}$. These sites see transport from polluted urban areas, and they likely also see transport of emissions from oil and gas drilling as discussed in more detail below. Some of 
Table 2. Summary of the observation sites used in CarbonTracker- $\mathrm{CH}_{4}$, and the performance of the assimilation scheme at each site. "\#Obs." and "\#Rej." are the number of observations available and the number of observations for which the prior simulated concentrations deviate more than $3 \sigma$ from the observations using a normal distribution defined with the observed value as the mean and the model-data mismatch error (MDM) as the standard deviation. The bias is the long-term mean of the posterior residuals (simulated-observed), $\sigma$ is the standard deviation of the residuals for each site, and $\mathrm{C} 2$ is the chi-squared statistic calculated as the mean residual divided by the prior uncertainty (Simulated-Observed $/(\mathbf{H} Q \mathbf{H}+R)$; where $\mathbf{H}$ is the matrix of transport response, $Q$ is the prior flux uncertainty and $R$ is the model-data mismatch error).

\begin{tabular}{|c|c|c|c|c|c|c|c|c|c|c|}
\hline Site Code & Lab & Lat. & Lon. & $\begin{array}{c}\text { Elev. } \\
\text { m a.s.l. }\end{array}$ & $\begin{array}{r}\# \\
\text { Obs. }\end{array}$ & $\begin{array}{r}\# \\
\text { Rej. }\end{array}$ & $\begin{array}{r}\mathrm{MDM} \\
\mathrm{ppb}\end{array}$ & $\begin{array}{r}\text { Bias } \\
\text { ppb }\end{array}$ & $\begin{array}{r}\sigma \\
\mathrm{ppb}\end{array}$ & $\chi^{2}$ \\
\hline abp_01d0 & ESRL & $12.77^{\circ} \mathrm{S}$ & $38.17^{\circ} \mathrm{W}$ & 1.0 & 112 & 3 & 7.5 & -8.4 & 7.7 & 2.0 \\
\hline alt_01d0 & ESRL & $82.45^{\circ} \mathrm{N}$ & $62.51^{\circ} \mathrm{W}$ & 200.0 & 532 & 0 & 15.0 & -2.2 & 8.7 & 0.3 \\
\hline alt_06c0 & $\mathrm{EC}$ & $82.45^{\circ} \mathrm{N}$ & $62.51^{\circ} \mathrm{W}$ & 200.0 & 3181 & 10 & 15.0 & -1.2 & 10.2 & 0.4 \\
\hline amt_01d0 & ESRL & $45.03^{\circ} \mathrm{N}$ & $68.68^{\circ} \mathrm{W}$ & 50.0 & 267 & 4 & 30.0 & -6.1 & 22.8 & 0.4 \\
\hline amt_01p0 & ESRL & $45.03^{\circ} \mathrm{N}$ & $68.68^{\circ} \mathrm{W}$ & 50.0 & 174 & 0 & 30.0 & 0.8 & 16.5 & 0.3 \\
\hline asc_01d0 & ESRL & $7.97^{\circ} \mathrm{S}$ & $14.4^{\circ} \mathrm{W}$ & 74.5 & 961 & 79 & 7.5 & -10.0 & 9.3 & 3.0 \\
\hline ask_01d0 & ESRL & $23.18^{\circ} \mathrm{N}$ & $5.42^{\circ} \mathrm{E}$ & 2728.0 & 491 & 0 & 25.0 & -6.9 & 9.1 & 0.2 \\
\hline azr_01d0 & ESRL & $38.77^{\circ} \mathrm{N}$ & $27.38^{\circ} \mathrm{W}$ & 40.0 & 350 & 16 & 15.0 & -12.0 & 15.9 & 1.7 \\
\hline bal_01d0 & ESRL & $55.35^{\circ} \mathrm{N}$ & $17.22^{\circ} \mathrm{E}$ & 3.0 & 974 & 0 & 75.0 & 1.4 & 29.4 & 0.1 \\
\hline bhd_01d0 & ESRL & $41.41^{\circ} \mathrm{S}$ & $174.87^{\circ} \mathrm{E}$ & 85.0 & 165 & 0 & 7.5 & -4.1 & 5.4 & 0.7 \\
\hline bkt_01d0 & ESRL & $0.2^{\circ} \mathrm{S}$ & $100.32^{\circ} \mathrm{E}$ & 864.5 & 345 & 0 & 75.0 & 6.8 & 30.8 & 0.2 \\
\hline bme_01d0 & ESRL & $32.37^{\circ} \mathrm{N}$ & $64.65^{\circ} \mathrm{W}$ & 30.0 & 256 & 14 & 15.0 & -13.6 & 17.4 & 2.1 \\
\hline bmw_01d0 & ESRL & $32.27^{\circ} \mathrm{N}$ & $64.88^{\circ} \mathrm{W}$ & 30.0 & 352 & 7 & 15.0 & -13.2 & 12.8 & 1.4 \\
\hline brw_01d0 & ESRL & $71.32^{\circ} \mathrm{N}$ & $156.61^{\circ} \mathrm{W}$ & 11.0 & 514 & 13 & 15.0 & -5.8 & 16.1 & 1.1 \\
\hline bsc_01d0 & ESRL & $44.17^{\circ} \mathrm{N}$ & $28.68^{\circ} \mathrm{E}$ & 3.0 & 501 & 1 & 75.0 & -14.4 & 56.2 & 0.5 \\
\hline cba_01d0 & ESRL & $55.21^{\circ} \mathrm{N}$ & $162.72^{\circ} \mathrm{W}$ & 21.34 & 892 & 23 & 15.0 & -10.6 & 13.4 & 1.1 \\
\hline cdl_06c0 & $\mathrm{EC}$ & $53.99^{\circ} \mathrm{N}$ & $105.12^{\circ} \mathrm{W}$ & 600.0 & 1390 & 77 & 25.0 & -24.7 & 30.3 & 2.1 \\
\hline cgo_01d0 & ESRL & $40.68^{\circ} \mathrm{S}$ & $144.69^{\circ} \mathrm{E}$ & 94.0 & 416 & 0 & 7.5 & -4.1 & 4.6 & 0.6 \\
\hline chr_01d0 & ESRL & $1.7^{\circ} \mathrm{N}$ & $157.17^{\circ} \mathrm{W}$ & 3.0 & 426 & 79 & 7.5 & -14.6 & 9.9 & 5.2 \\
\hline crz_01d0 & ESRL & $46.45^{\circ} \mathrm{S}$ & $51.85^{\circ} \mathrm{E}$ & 120.0 & 453 & 0 & 7.5 & -2.9 & 4.3 & 0.5 \\
\hline egb_06c0 & $\mathrm{EC}$ & $44.23^{\circ} \mathrm{N}$ & $79.78^{\circ} \mathrm{W}$ & 251.0 & 1810 & 0 & 75.0 & -6.9 & 28.7 & 0.1 \\
\hline eic_01d0 & ESRL & $27.15^{\circ} \mathrm{S}$ & $109.45^{\circ} \mathrm{W}$ & 50.0 & 323 & 3 & 7.5 & -7.3 & 5.3 & 1.4 \\
\hline esp_06c0 & $\mathrm{EC}$ & $49.58^{\circ} \mathrm{N}$ & $126.37^{\circ} \mathrm{W}$ & 7.0 & 403 & 0 & 25.0 & -6.8 & 12.3 & 0.3 \\
\hline etl_06c0 & $\mathrm{EC}$ & $54.35^{\circ} \mathrm{N}$ & $104.98^{\circ} \mathrm{W}$ & 492.0 & 1780 & 135 & 25.0 & -30.1 & 31.9 & 2.8 \\
\hline fsd_06c0 & $\mathrm{EC}$ & $49.88^{\circ} \mathrm{N}$ & $81.57^{\circ} \mathrm{W}$ & 210.0 & 3409 & 10 & 25.0 & -9.4 & 18.3 & 0.6 \\
\hline gmi_01d0 & ESRL & $13.43^{\circ} \mathrm{N}$ & $144.78^{\circ} \mathrm{E}$ & 3.0 & 802 & 11 & 15.0 & -10.2 & 13.0 & 1.2 \\
\hline hba_01d0 & ESRL & $75.58^{\circ} \mathrm{S}$ & $26.5^{\circ} \mathrm{W}$ & 30.0 & 506 & 0 & 7.5 & 0.5 & 4.6 & 0.3 \\
\hline hpb_01d0 & ESRL & $47.8^{\circ} \mathrm{N}$ & $11.01^{\circ} \mathrm{E}$ & 985.0 & 241 & 17 & 25.0 & -13.8 & 35.7 & 1.4 \\
\hline hun_01d0 & ESRL & $46.95^{\circ} \mathrm{N}$ & $16.65^{\circ} \mathrm{E}$ & 248.0 & 530 & 3 & 75.0 & -14.0 & 43.7 & 0.3 \\
\hline ice_01d0 & ESRL & $63.4^{\circ} \mathrm{N}$ & $20.29^{\circ} \mathrm{W}$ & 118.0 & 529 & 7 & 15.0 & -3.3 & 13.1 & 0.6 \\
\hline izo_01d0 & ESRL & $28.31^{\circ} \mathrm{N}$ & $16.5^{\circ} \mathrm{W}$ & 2360.0 & 443 & 2 & 15.0 & -8.5 & 11.4 & 0.9 \\
\hline key_01d0 & ESRL & $25.67^{\circ} \mathrm{N}$ & $80.16^{\circ} \mathrm{W}$ & 3.0 & 388 & 3 & 25.0 & -7.0 & 20.1 & 0.6 \\
\hline kum_01d0 & ESRL & $19.52^{\circ} \mathrm{N}$ & $154.82^{\circ} \mathrm{W}$ & 3.0 & 720 & 42 & 7.5 & -6.8 & 10.6 & 2.2 \\
\hline kzd_01d0 & ESRL & $44.06^{\circ} \mathrm{N}$ & $76.82^{\circ} \mathrm{E}$ & 601.0 & 454 & 4 & 75.0 & 5.2 & 44.0 & 0.2 \\
\hline kzm_01d0 & ESRL & $43.25^{\circ} \mathrm{N}$ & $77.88^{\circ} \mathrm{E}$ & 2519.0 & 447 & 2 & 25.0 & -2.8 & 20.2 & 0.6 \\
\hline lef_01d0 & ESRL & $45.95^{\circ} \mathrm{N}$ & $90.27^{\circ} \mathrm{W}$ & 472.0 & 505 & 6 & 30.0 & -9.7 & 28.6 & 0.8 \\
\hline lef_01p0 & ESRL & $45.95^{\circ} \mathrm{N}$ & $90.27^{\circ} \mathrm{W}$ & 472.0 & 341 & 7 & 30.0 & -2.1 & 30.9 & 0.9 \\
\hline 1lb_06c0 & $\mathrm{EC}$ & $54.95^{\circ} \mathrm{N}$ & $112.45^{\circ} \mathrm{W}$ & 540.0 & 1152 & 84 & 75.0 & -79.9 & 122.4 & 3.7 \\
\hline 1ln_01d0 & ESRL & $23.47^{\circ} \mathrm{N}$ & $120.87^{\circ} \mathrm{E}$ & 2862.0 & 222 & 1 & 25.0 & -4.1 & 24.4 & 0.9 \\
\hline Imp_01d0 & ESRL & $35.52^{\circ} \mathrm{N}$ & $12.62^{\circ} \mathrm{E}$ & 45.0 & 206 & 1 & 25.0 & -0.7 & 20.5 & 0.5 \\
\hline mhd_01d0 & ESRL & $53.33^{\circ} \mathrm{N}$ & $9.9^{\circ} \mathrm{W}$ & 5.0 & 416 & 0 & 25.0 & -4.6 & 11.4 & 0.2 \\
\hline mid_01d0 & ESRL & $28.21^{\circ} \mathrm{N}$ & $177.38^{\circ} \mathrm{W}$ & 3.7 & 525 & 5 & 15.0 & -10.7 & 10.9 & 1.0 \\
\hline mkn_01d0 & ESRL & $0.05^{\circ} \mathrm{S}$ & $37.3^{\circ} \mathrm{E}$ & 3897.0 & 146 & 0 & 25.0 & -14.3 & 14.8 & 0.7 \\
\hline mlo_01d0 & ESRL & $19.54^{\circ} \mathrm{N}$ & $155.58^{\circ} \mathrm{W}$ & 3397.0 & 565 & 0 & 15.0 & -2.4 & 10.9 & 0.5 \\
\hline nmb_01d0 & ESRL & $23.58^{\circ} \mathrm{S}$ & $15.03^{\circ} \mathrm{E}$ & 456.0 & 164 & 0 & 25.0 & -7.8 & 11.4 & 0.3 \\
\hline nwr_01d0 & ESRL & $40.05^{\circ} \mathrm{N}$ & $105.58^{\circ} \mathrm{W}$ & 3523.0 & 543 & 18 & 15.0 & -11.1 & 15.2 & 1.5 \\
\hline oxk_01d0 & ESRL & $50.03^{\circ} \mathrm{N}$ & $11.8^{\circ} \mathrm{E}$ & 1022.0 & 202 & 2 & 75.0 & -12.5 & 42.9 & 0.3 \\
\hline pal_01d0 & ESRL & $67.97^{\circ} \mathrm{N}$ & $24.12^{\circ} \mathrm{E}$ & 560.0 & 377 & 54 & 15.0 & 16.7 & 35.1 & 0.2 \\
\hline poc000_01d1 & ESRL & $0.0^{\circ} \mathrm{N}$ & $155.0^{\circ} \mathrm{W}$ & 10.0 & 173 & 33 & 7.5 & -13.9 & 9.5 & 4.7 \\
\hline pocn05_01D1 & ESRL & $5.0^{\circ} \mathrm{N}$ & $151.0^{\circ} \mathrm{W}$ & 10.0 & 174 & 29 & 7.5 & -15.1 & 9.5 & 5.3 \\
\hline
\end{tabular}


Table 2. Continued.

\begin{tabular}{|c|c|c|c|c|c|c|c|c|c|c|}
\hline Site Code & Lab & Lat. & Lon. & $\begin{array}{c}\text { Elev. } \\
\text { m a.s.1. }\end{array}$ & $\begin{array}{r}\# \\
\text { Obs. }\end{array}$ & $\begin{array}{r}\# \\
\text { Rej. }\end{array}$ & $\begin{array}{r}\text { MDM } \\
\text { ppb }\end{array}$ & $\begin{array}{r}\text { Bias } \\
\text { ppb }\end{array}$ & $\begin{array}{r}\sigma \\
\mathrm{ppb}\end{array}$ & $\chi^{2}$ \\
\hline pocn10_01D1 & ESRL & $10.0^{\circ} \mathrm{N}$ & $149.0^{\circ} \mathrm{W}$ & 10.0 & 174 & 45 & 7.5 & -16.0 & 14.0 & 7.6 \\
\hline pocn15_01D1 & ESRL & $15.0^{\circ} \mathrm{N}$ & $145.0^{\circ} \mathrm{W}$ & 10.0 & 168 & 26 & 7.5 & -11.0 & 11.1 & 4.1 \\
\hline pocn20_01D1 & ESRL & $20.0^{\circ} \mathrm{N}$ & $141.0^{\circ} \mathrm{W}$ & 10.0 & 166 & 13 & 7.5 & -6.8 & 11.5 & 2.9 \\
\hline pocn25_01D1 & ESRL & $25.0^{\circ} \mathrm{N}$ & $139.0^{\circ} \mathrm{W}$ & 10.0 & 155 & 14 & 7.5 & -7.0 & 11.2 & 2.6 \\
\hline pocn30_01D1 & ESRL & $30.0^{\circ} \mathrm{N}$ & $135.0^{\circ} \mathrm{W}$ & 10.0 & 153 & 18 & 7.5 & -4.7 & 13.9 & 2.7 \\
\hline pocn35_01D1 & ESRL & $35.0^{\circ} \mathrm{N}$ & $137.0^{\circ} \mathrm{W}$ & 10.0 & 5 & 0 & 7.5 & -4.0 & 8.6 & 1.4 \\
\hline pocs05_01D1 & ESRL & $5.0^{\circ} \mathrm{S}$ & $159.0^{\circ} \mathrm{W}$ & 10.0 & 159 & 31 & 7.5 & -15.3 & 8.6 & 5.2 \\
\hline pocs10_01D1 & ESRL & $10.0^{\circ} \mathrm{S}$ & $161.0^{\circ} \mathrm{W}$ & 10.0 & 170 & 41 & 7.5 & -14.6 & 10.1 & 5.4 \\
\hline pocs15_01D1 & ESRL & $15.0^{\circ} \mathrm{S}$ & $171.0^{\circ} \mathrm{W}$ & 10.0 & 163 & 15 & 7.5 & -10.4 & 9.5 & 3.4 \\
\hline pocs20_01D1 & ESRL & $20.0^{\circ} \mathrm{S}$ & $174.0^{\circ} \mathrm{W}$ & 10.0 & 169 & 8 & 7.5 & -7.3 & 7.9 & 2.0 \\
\hline pocs25_01D1 & ESRL & $25.0^{\circ} \mathrm{S}$ & $171.0^{\circ} \mathrm{W}$ & 10.0 & 164 & 0 & 7.5 & -5.3 & 6.3 & 1.1 \\
\hline pocs30_01D1 & ESRL & $30.0^{\circ} \mathrm{S}$ & $176.0^{\circ} \mathrm{W}$ & 10.0 & 166 & 0 & 7.5 & -5.0 & 5.0 & 0.8 \\
\hline pocs35_01D1 & ESRL & $35.0^{\circ} \mathrm{S}$ & $180.0^{\circ} \mathrm{E}$ & 10.0 & 14 & 1 & 7.5 & -0.5 & 8.2 & 0.5 \\
\hline psa_01d0 & ESRL & $64.92^{\circ} \mathrm{S}$ & $64.0^{\circ} \mathrm{W}$ & 10.0 & 542 & 0 & 7.5 & -2.7 & 3.7 & 0.3 \\
\hline pta_01d0 & ESRL & $38.95^{\circ} \mathrm{N}$ & $123.74^{\circ} \mathrm{W}$ & 17.0 & 427 & 1 & 25.0 & -4.6 & 16.9 & 0.4 \\
\hline rpb_01d0 & ESRL & $13.17^{\circ} \mathrm{N}$ & $59.43^{\circ} \mathrm{W}$ & 45.0 & 519 & 2 & 15.0 & -10.7 & 10.0 & 0.9 \\
\hline sct_01p0 & ESRL & $33.41^{\circ} \mathrm{N}$ & $81.83^{\circ} \mathrm{W}$ & 115.2 & 351 & 0 & 75.0 & -23.5 & 33.7 & 0.3 \\
\hline sey_01d0 & ESRL & $4.67^{\circ} \mathrm{S}$ & $55.17^{\circ} \mathrm{E}$ & 3.0 & 514 & 43 & 7.5 & -6.5 & 12.3 & 3.1 \\
\hline sgp_01d0 & ESRL & $36.8^{\circ} \mathrm{N}$ & $97.5^{\circ} \mathrm{W}$ & 314.0 & 443 & 10 & 75.0 & -56.1 & 57.4 & 0.8 \\
\hline shm_01d0 & ESRL & $52.72^{\circ} \mathrm{N}$ & $174.1^{\circ} \mathrm{E}$ & 40.0 & 482 & 0 & 25.0 & -8.7 & 11.4 & 0.3 \\
\hline smo_01d0 & ESRL & $14.25^{\circ} \mathrm{S}$ & $170.56^{\circ} \mathrm{W}$ & 42.0 & 568 & 70 & 7.5 & -10.5 & 9.9 & 3.6 \\
\hline spo_01d0 & ESRL & $89.98^{\circ} \mathrm{S}$ & $24.8^{\circ} \mathrm{W}$ & 2810.0 & 566 & 0 & 7.5 & -4.1 & 4.7 & 0.7 \\
\hline stm_01d0 & ESRL & $66.0^{\circ} \mathrm{N}$ & $2.0^{\circ} \mathrm{E}$ & 0.0 & 917 & 9 & 15.0 & -1.4 & 13.5 & 0.5 \\
\hline sum_01d0 & ESRL & $72.58^{\circ} \mathrm{N}$ & $38.48^{\circ} \mathrm{W}$ & 3238.0 & 468 & 0 & 15.0 & -4.7 & 8.4 & 0.4 \\
\hline syo_01d0 & ESRL & $69.0^{\circ} \mathrm{S}$ & $39.58^{\circ} \mathrm{E}$ & 11.0 & 260 & 0 & 7.5 & -2.6 & 3.6 & 0.3 \\
\hline tap_01d0 & ESRL & $36.73^{\circ} \mathrm{N}$ & $126.13^{\circ} \mathrm{E}$ & 20.0 & 441 & 3 & 75.0 & 10.2 & 61.7 & 0.5 \\
\hline tdf_01d0 & ESRL & $54.87^{\circ} \mathrm{S}$ & $68.48^{\circ} \mathrm{W}$ & 20.0 & 206 & 0 & 7.5 & -4.2 & 4.1 & 0.6 \\
\hline thd_01d0 & ESRL & $41.05^{\circ} \mathrm{N}$ & $124.15^{\circ} \mathrm{W}$ & 107.0 & 400 & 0 & 25.0 & -7.0 & 14.6 & 0.4 \\
\hline uta_01d0 & ESRL & $39.9^{\circ} \mathrm{N}$ & $113.72^{\circ} \mathrm{W}$ & 1320.0 & 525 & 12 & 25.0 & -5.5 & 28.7 & 0.4 \\
\hline uum_01d0 & ESRL & $44.45^{\circ} \mathrm{N}$ & $111.1^{\circ} \mathrm{E}$ & 914.0 & 533 & 1 & 25.0 & -1.2 & 22.7 & 0.3 \\
\hline wbi_01p0 & ESRL & $41.72^{\circ} \mathrm{N}$ & $91.35^{\circ} \mathrm{W}$ & 241.7 & 296 & 12 & 30.0 & -8.3 & 38.0 & 1.4 \\
\hline wgc_01p0 & ESRL & $38.27^{\circ} \mathrm{N}$ & $121.49^{\circ} \mathrm{W}$ & 0.0 & 339 & 53 & 75.0 & -118 & 158.8 & 6.9 \\
\hline wis_01d0 & ESRL & $31.13^{\circ} \mathrm{N}$ & $34.88^{\circ} \mathrm{E}$ & 400.0 & 552 & 3 & 25.0 & -6.2 & 23.7 & 0.8 \\
\hline wkt_01d0 & ESRL & $31.31^{\circ} \mathrm{N}$ & $97.33^{\circ} \mathrm{W}$ & 251.0 & 409 & 55 & 30.0 & -48.6 & 43.7 & 3.8 \\
\hline wkt_01p0 & ESRL & $31.31^{\circ} \mathrm{N}$ & $97.33^{\circ} \mathrm{W}$ & 251.0 & 298 & 38 & 30.0 & -46.7 & 58.7 & 5.8 \\
\hline wlg_01d0 & ESRL & $36.29^{\circ} \mathrm{N}$ & $100.9^{\circ} \mathrm{E}$ & 3810.0 & 462 & 17 & 15.0 & -1.8 & 20.6 & 0.8 \\
\hline wsa_06c0 & $\mathrm{EC}$ & $49.93^{\circ} \mathrm{N}$ & $60.02^{\circ} \mathrm{W}$ & 5.0 & 2314 & 52 & 25.0 & 3.8 & 25.5 & 0.9 \\
\hline zep_01d0 & ESRL & $78.9^{\circ} \mathrm{N}$ & $11.88^{\circ} \mathrm{E}$ & 475.0 & 588 & 11 & 15.0 & 2.2 & 14.2 & 0.5 \\
\hline
\end{tabular}

the Environment Canada sites also have large negative biases. LLB (Lac Labiche, Canada) for example, has an average residual of $-80 \mathrm{ppb}$, and it is located close to possible wetland sources as well as fossil fuel operations.

\subsection{Comparison to aircraft profiles}

The current version of CarbonTracker- $\mathrm{CH}_{4}$ does not assimilate observations from the NOAA GMD aircraft project. This network currently consists of 17 sites distributed over North America where air samples are collected at 12 altitudes and analyzed for a suite of atmospheric gases, including $\mathrm{CH}_{4}$ (http://www.esrl.noaa.gov/gmd/ccgg/aircraft/). Because the aircraft observations were not used to constrain the inversion, these data can be used as an independent check on the inversion. In addition, they provide useful insight into the performance of TM5's vertical transport.

Figure 4 shows the prior and posterior residuals for THD (Trinidad Head, CA), where the white line represents the average of the residuals and the red lines show the standard deviation of the residuals as a function of altitude. Compared to the prior residuals, the posterior residuals show a reduction in bias at all altitudes, as well as a smaller spread in the residuals. At high altitudes the surface data constraints have resulted in estimated emissions that are in good agreement with the well-mixed free tropospheric abundances. THD shows good agreement at the lowest levels because profiles at this 


\section{Residuals}
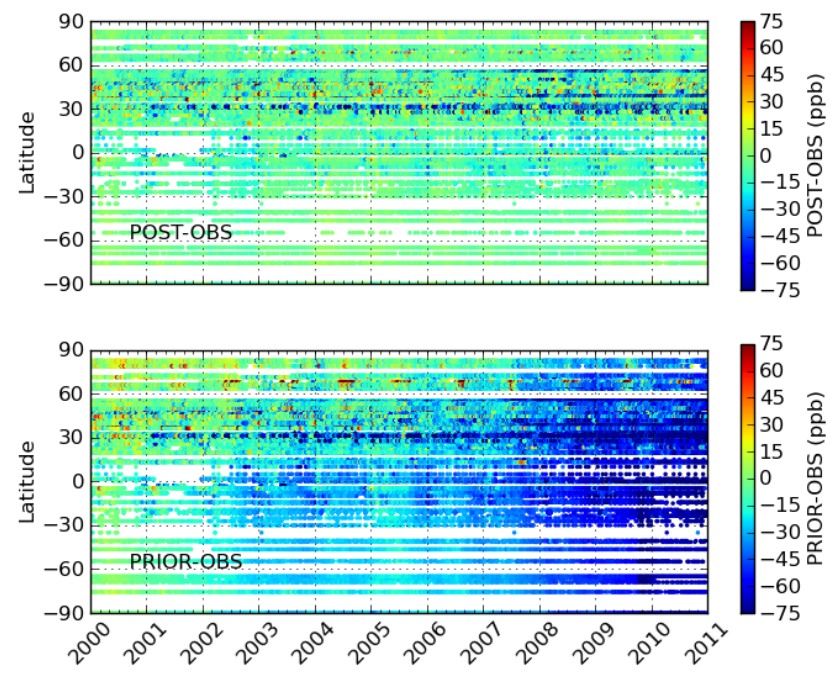

Figure 2. The CarbonTracker posterior residuals (simulated minus observed, in nmol mol-1) as a function of time and latitude (top) and prior residuals (bottom). Each dot represents the time and location of a $\mathrm{CH}_{4}$ observation that was assimilated in CarbonTracker. Colors represent the difference between the final simulated value and the actual measurement, with warm colors indicating that CarbonTracker simulates too much methane compared to observations, and cool colors indicating that CarbonTracker estimates too little.

location are more likely to sample background marine air coming off of the Pacific Ocean. In contrast, the continental site, DND (Dahlen, North Dakota) shows a much larger negative bias at low altitudes during the summer but good agreement at all levels during winter (Fig. 5). This implies that local or regional-scale sources that are not included in the CarbonTracker- $\mathrm{CH}_{4}$ prior and are not "seen" by other sites influence these summertime profiles. Similar results are found for other aircraft sites distributed throughout the central US Some sites, however, show larger biases near the surface. Figure 6 shows both prior and posterior residuals at TGC (Texas Gulf Coast), a site that sees both continental and marine air, and also air from nearby industrial and urban centers along the Texas Gulf Coast. Even after the inversion, the residuals near the surface are still quite large indicating that the priors and the observations constraining are not able to account for strong local sources.

Figure 7 shows prior and posterior residuals for Poker Flat, Alaska. Note that even after the inversion, methane abundance is underestimated near the surface. This is likely the result of underestimation of prior wetland emissions, along with observational constraints that contain information about interior Alaska. On the other hand, as we will show below Arctic sites sampling background air likely capture the large scale methane budget fairly well. Figure 7 demonstrates the importance of sampling sites near sources for constraining regional methane budgets. Future versions of

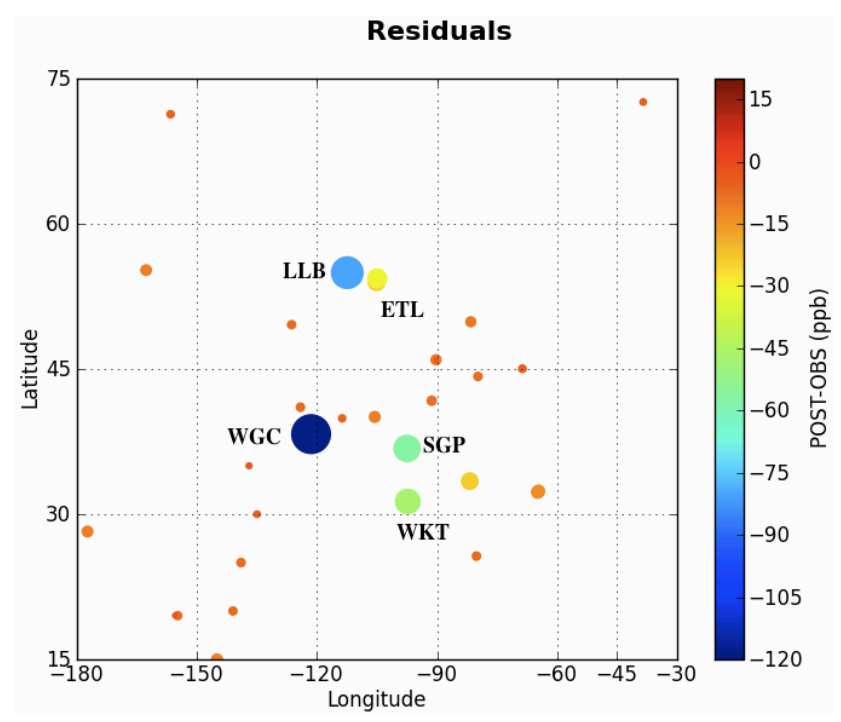

Figure 3. The CarbonTracker posterior residuals (simulated minus observed, in nmol mol-1) as a function of time and latitude for North America. Each bubble has a radius proportional to the size of the residual, and the values are also indicated by the color bar. The largest residuals found by CarbonTracker- $\mathrm{CH}_{4}$ are labeled also by site code.

\section{THD_01P2 (Not Assimilated)}
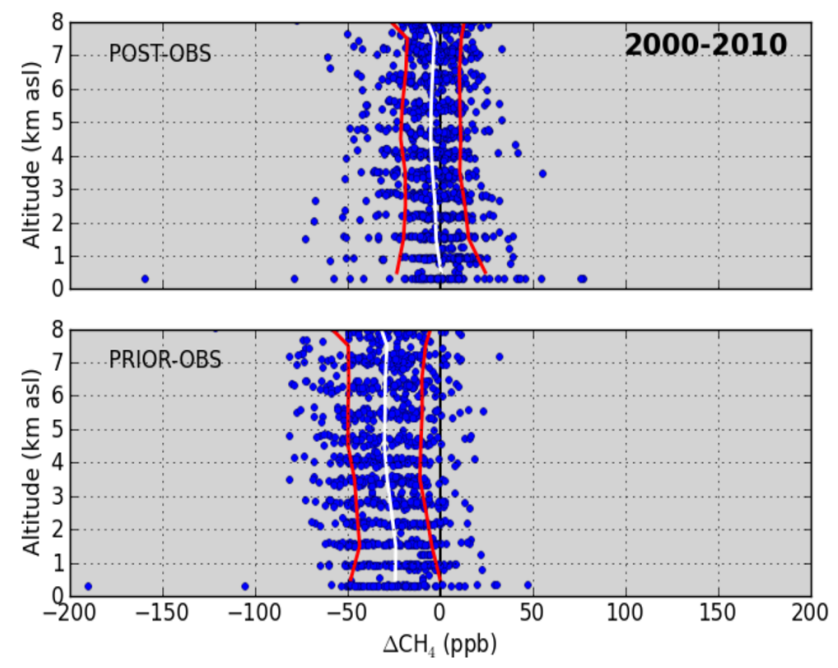

Figure 4. Statistical summary of residuals for aircraft profiles at a site sampling marine air (Trinidad Head, CA). Units are $10^{-9} \mathrm{~mol} \mathrm{~mol}^{-1}$ of $\mathrm{CH}_{4}$ (ppb). The top figure shows the postassimilation residuals (posterior-observed) and the bottom figure shows the residuals with no data assimilation (prior-observed). Aircraft data are not currently assimilated in CarbonTracker so they provide an independent evaluation of the data assimilation. Ideally, the mean of the residuals for the simulations with data assimilation should be near zero. The residuals for the simulations without data assimilation, on the other hand, tend to show large biases. 


\section{DND_01P2 (Not Assimilated)}
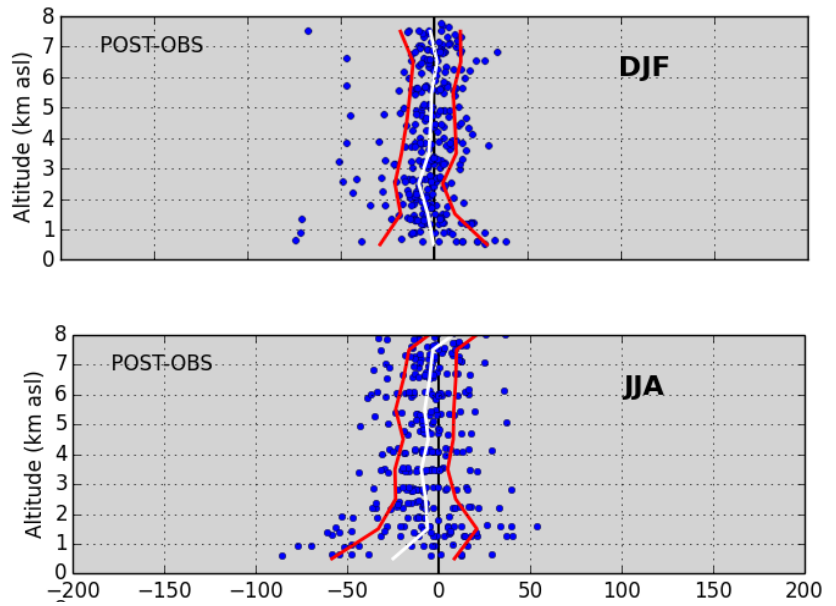

Figure 5. Statistical summary of residuals for aircraft profiles at a site sampling continental air (Dahlen, $\mathrm{ND} ; 47.5^{\circ} \mathrm{N}, 99.2^{\circ} \mathrm{W}$ ). Units are $10^{-9} \mathrm{~mol} \mathrm{~mol}^{-1}$ of $\mathrm{CH}_{4}(\mathrm{ppb})$. The top figure shows the postassimilation residuals (posterior-observed) for winter months and the bottom figure shows the post-assimilation residuals for summer months. Note that summertime emissions near the surface are underestimated. Aircraft data are not currently assimilated in CarbonTracker so they provide an independent evaluation of the data assimilation. Ideally, the mean of the residuals for the simulations with data assimilation should be near zero. The residuals for the simulations without data assimilation, on the other hand, tend to show large biases.

CarbonTracker- $\mathrm{CH}_{4}$ may use at least the lower levels of the aircraft observations in order to better constrain emissions.

\subsection{Global and zonal averages}

The abundance of $\mathrm{CH}_{4}$ integrated over the global atmosphere and its growth rate are important diagnostics of inversion performance (Rayner et al., 2005; Bruhwiler et al., 2011; Bergamaschi et al., 2013) because given the $\sim 10 \mathrm{yr}$ lifetime of $\mathrm{CH}_{4}$, on global scales emissions and sinks must balance in a way that produces the observed global growth of $\mathrm{CH}_{4}$. Here we follow the approach taken by Bruhwiler et al. (2011) that uses the same sampling, filtering and smoothing procedure used to produce the observed global and zonal $\mathrm{CH}_{4}$ abundances for both data and model output (see Masarie and Tans (1995) and web updates at http://www.esrl.noaa.gov/gmd for a description of the data extension procedure). Zonal averages are constructed using mainly marine boundary later sites by removing a long term trend approximated as a quadratic function, deseasonalizing by subtracting an average seasonal cycle, and using a low-pass digital filter with a half width of 40 days. Importantly, the model is sampled at the same times as the observations and missing data are filled in the same way for both the observations and simulations. The simu-
TGC_01P2 (Not Assimilated)

$(27.73 \mathrm{~N}, 96.86 \mathrm{~W})$
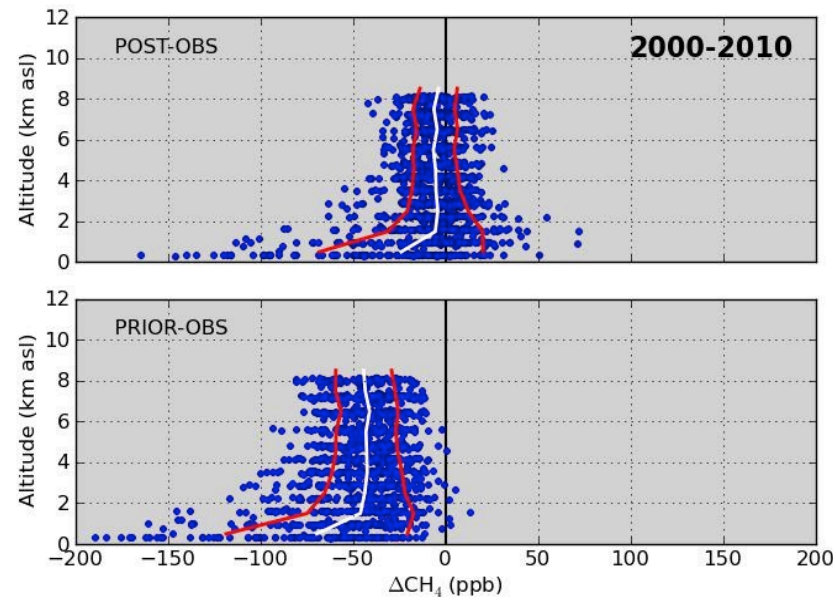

Figure 6. Statistical summary of residuals for aircraft profiles at a site sampling continental and marine air near strong local sources. Units are $10^{-9} \mathrm{~mol} \mathrm{~mol}^{-1}$ of $\mathrm{CH}_{4}$ (ppb). The top figure shows the post-assimilation residuals (posterior-observed) for and the bottom figure shows the pre-assimilation residuals (prior-observed). The mean of the residuals for the simulations with data assimilation should be near zero. The residuals for the simulations without data assimilation, on the other hand, tend to show large biases.

PFA_01P2 (Not Assimilated) $(65.07 \mathrm{~N}, 147.29 \mathrm{~W})$
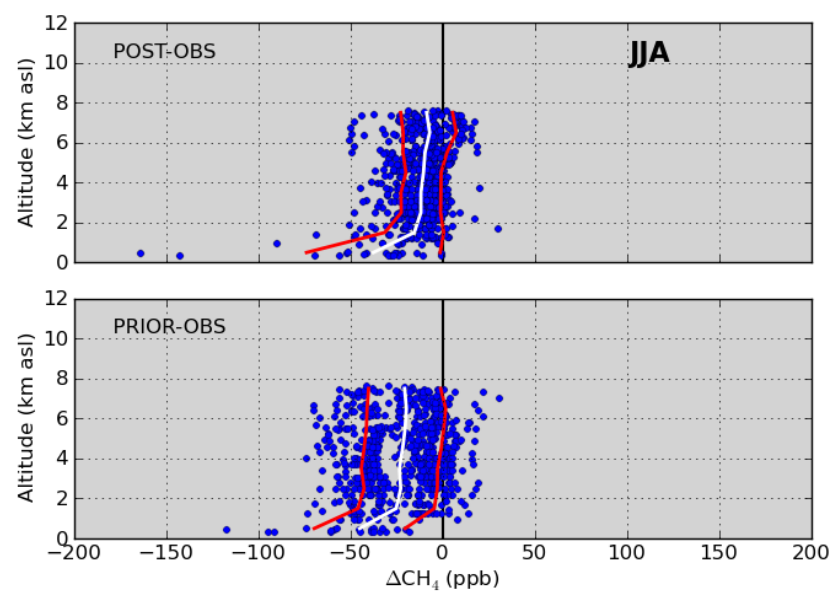

Figure 7. Statistical summary of residuals for aircraft profiles at a high latitude site in Alaska during boreal summer. Units are $10^{-9} \mathrm{~mol} \mathrm{~mol}^{-1}$ of $\mathrm{CH}_{4}$ (ppb). The top figure shows the postassimilation residuals (posterior-observed) for and the bottom figure shows the pre-assimilation residuals (prior-observed). The mean of the residuals for the simulations with data assimilation should be near zero. The residuals for the simulations without data assimilation, on the other hand, tend to show large biases. 
Global
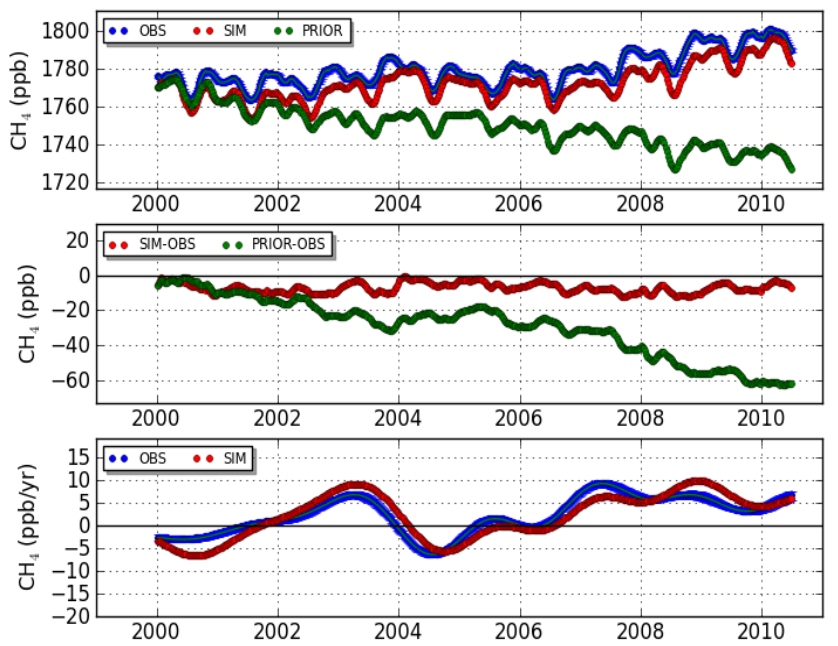

Figure 8. (Top) De-seasonalized time series of observed (dark blue, "OBS", with very small error bars estimated using a bootstrap technique), assimilated (red, "SIM") and prior (green, "PRIOR") average methane mole fraction. For the "PRIOR" simulations, prior fluxes were used to calculate $\mathrm{CH}_{4}$ mole fractions, while for the "SIM" simulations $\mathrm{CH}_{4}$ was calculated using fluxes that were adjusted for optimal agreement with atmospheric observations. Units are ppb $\left(10^{-9} \mathrm{~mol} \mathrm{~mol}^{-1}\right)$. (Middle) The differences from observations for assimilated and prior $\mathrm{CH}_{4}$ (ppb). (Bottom) Derived growth rate of $\mathrm{CH}_{4}$ mole fraction for observed (with error bars) and assimilated $\mathrm{CH}_{4}$ mole fraction. The growth rate is computed by taking the first derivative of the average mole fractions shown in the top figure. Units are $\mathrm{ppb} \mathrm{yr}^{-1}\left(10^{-9} \mathrm{~mol} \mathrm{~mol}^{-1} \mathrm{yr}^{-1}\right)$.

lated and observed zonal averages are therefore comparable. As shown in the top panel of Fig. 8, the global posterior $\mathrm{CH}_{4}$ abundance produced by the CarbonTracker- $\mathrm{CH}_{4}$ assimilation is in fairly good agreement with the observed global abundance, however it is biased low by about $10 \mathrm{ppb}$. This is because the global abundance that results from use of the prior fluxes without optimization is much lower than observed, and the posterior global total represents a compromise between $\mathrm{CH}_{4}$ abundance obtained from prior flux estimates and the observations at each site. Reducing the model-data mismatch error and/or increasing the prior flux uncertainty would improve the agreement between posterior $\mathrm{CH}_{4}$ and the observations, but likely at the expense of having flux estimates with unrealistic spatiotemporal variability, especially in regions that are relatively unconstrained by observations. On the other hand, if the prior flux estimates are weighted too heavily in the inversion, the posterior global total more closely follows the global abundance simulated by the prior fluxes than the observations, and these may depart significantly from the actual emissions. The middle panel of Figure 8 shows the difference between the simulated and prior $\mathrm{CH}_{4}$ abundance and the observations, where it can be seen that the residual difference varies slightly over time as the bias re-
Polar Northern Hemisphere
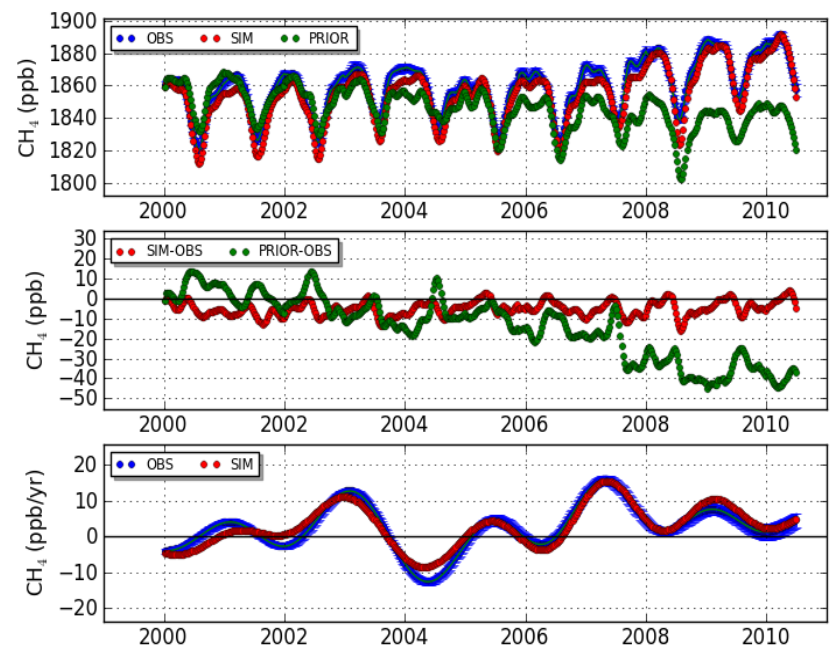

Figure 9. (Top) De-seasonalized time series of observed (dark blue, "OBS" with error bars), assimilated (red, "SIM") and prior (green, "PRIOR") average methane mole fraction for the polar Northern Hemisphere $\left(53-90^{\circ} \mathrm{N}\right)$. (Middle) Differences from observations for assimilated and prior $\mathrm{CH}_{4}$ (ppb). (Bottom) Derived growth rate of $\mathrm{CH}_{4}$ mole fraction for observed and assimilated $\mathrm{CH}_{4}$ mole fraction for the polar Northern Hemisphere.

sulting from prior emissions changes. In particular, between 2004 and 2006, the prior residuals are fairly constant and the residual between the posterior and the observations is smaller than over other periods. The conclusions that can be drawn from this are that better prior flux estimates are needed for future versions of CarbonTracker- $\mathrm{CH}_{4}$, and that the global abundance is a useful way to judge whether the solution is most influenced by the prior information or by the observational constraints.

The bottom panel of Fig. 8 shows the growth rate of global atmospheric $\mathrm{CH}_{4}$, a quantity that is directly related to imbalances between emissions and sinks. CarbonTracker- $\mathrm{CH}_{4}$ follows the observed growth rate fairly well, but not perfectly since there are periods for which it under- or overestimates the observed growth rate. During 2007, for example, the observed growth was underestimated by $\sim 30 \%$, while during 2009 it was overestimated by about the same amount. These differences are an indication of global total biases in estimated emissions. The posterior global growth rate of $\mathrm{CH}_{4}$ was also computed by Bergamaschi et al. (2013) for their inversions. They find a maximum growth rate of about $10 \mathrm{ppb} \mathrm{yr}^{-1}$ for 2007 , closer to the observed growth rate shown in Fig. 8 even when the surface observations only are used in the assimilation. This implies a possible role for the relatively short assimilation window of CarbonTracker in accounting for the underestimate in global growth. If the anomalous growth occurs in the tropics and this information cannot propagate to remote sites due to a short 
Tropics
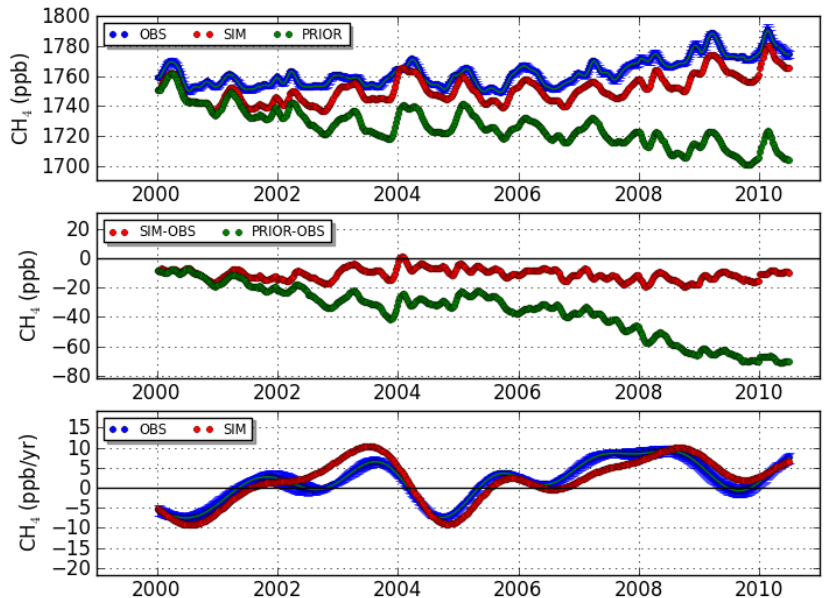

Figure 10. (Top) Time series of observed (dark blue, "OBS"), assimilated (red, "SIM") and prior (green, "PRIOR") average methane mole fraction for the tropics $\left(17.5^{\circ} \mathrm{S}-17.5^{\circ} \mathrm{N}\right)$. (Middle) Differences from observations for assimilated and prior $\mathrm{CH}_{4}$ (ppb). (Bottom) Derived growth rate of $\mathrm{CH}_{4}$ mole fraction for observed (with error bars) and assimilated $\mathrm{CH}_{4}$ mole fraction for the tropics.

window, variability will be missed. As discussed by Bruhwiler et al. (2005), an assimilation window of 12 weeks is ideal for the surface network, but computational issues prevented its use for this study. On the other hand Fig. 8 shows that the anomalous global growth is only slightly overestimated in 2003, while Bergamaschi et al. (2013) may underestimate this feature.

It is also informative to consider zonally averaged $\mathrm{CH}_{4}$ mole fraction and its growth rate at sub-hemispheric scales as shown in Fig. 9 for the high northern latitudes $\left(53.1-90^{\circ} \mathrm{N}\right)$, Fig. 10 for the tropics $\left(17.5^{\circ} \mathrm{S}-17.5^{\circ} \mathrm{N}\right)$ and Fig. 11 for the southern temperate latitudes $\left(17.5-53^{\circ} \mathrm{S}\right)$. For the high northern latitudes, the posterior simulated integrated $\mathrm{CH}_{4}$ is quite close to the observations and the growth rate agrees well with the observed growth rate. On the other hand, the simulated integrated $\mathrm{CH}_{4}$ in the tropics is further from the observations and closer to the prior than for the high northern latitudes. The posterior zonal average $\mathrm{CH}_{4}$ abundance is closer to the observations for the southern temperate latitude zone, however, the growth rate differences suggest some interannual variability differences, possibly the result of transport from tropical latitudes considering the relatively small contribution these latitudes make to the global methane budget. The simulated growth rate in the tropics also can differ significantly from the observed growth rate, with under or over estimates reaching $5 \mathrm{ppb} \mathrm{yr}^{-1}$ or more. As a comparison, the agreement between the observed and simulated growth rate at northern polar latitudes is usually well within a few $\mathrm{ppb} \mathrm{yr}^{-1}$. The middle panels of Figs. 9, 10 and 11 show that when the residuals between the prior and observations decrease, the posterior residuals are also smaller.
Temperate Southern Hemisphere
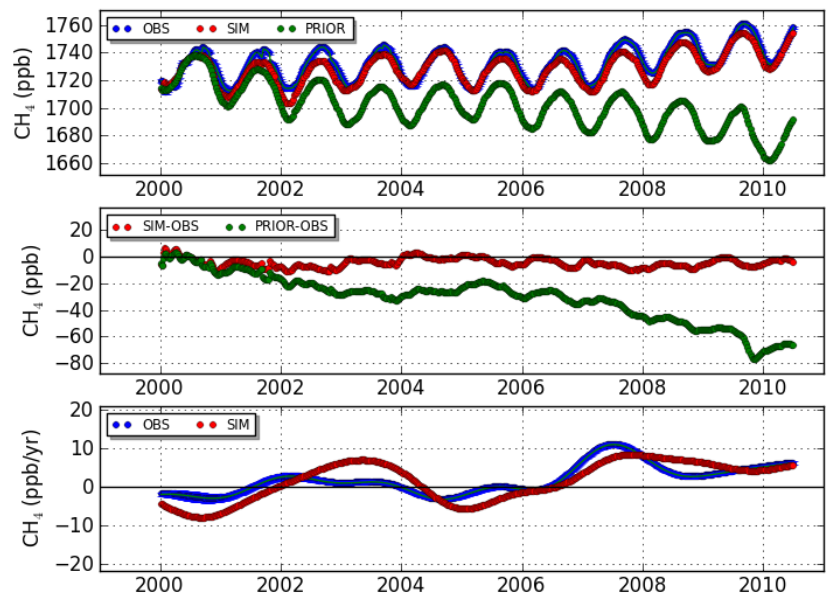

Figure 11. (Top) Time series of observed (dark blue, "OBS"), assimilated (red, "SIM") and prior (green, "PRIOR") average methane mole fraction for the temperate Southern Hemisphere $\left(17.5-53.3^{\circ} \mathrm{S}\right)$. (Middle) Differences from observations for assimilated and prior $\mathrm{CH}_{4}$ (ppb). (Bottom) Derived growth rate of $\mathrm{CH}_{4}$ mole fraction for observed (with error bars) and assimilated $\mathrm{CH}_{4}$ mole fraction for the tropics.

For the high northern latitudes, a small seasonal cycle in the residuals potentially provides some information about which emission processes may be under- or overestimated by the priors. Differences between simulated and observed $\mathrm{CH}_{4}$ are largest during the winter with the observations being higher than the simulations. This implies that mid- and high latitude emissions from anthropogenic sources may be underestimated by the priors and not completely corrected for by the inversion. Note that biogenic emissions at midand high latitudes are at a minimum during winter.

Anomalously high growth rates were observed in 2007 both in the Arctic and in the tropics (Dlugokencky et al., 2009), a year when the Arctic was anomalously warm and the tropics were unusually wet. The results shown in Fig. 9 suggest that the inversion is likely able to provide good estimates of flux anomalies in high latitudes, at least in the zonal average. For the tropics, zonal average flux anomaly estimates for this year are likely to be underestimated. These differences in the ability of the inversion to recover and attribute variability are due mostly to differences in the distribution of network sites with the Arctic having better observational coverage than the tropics. Another factor is that the deep vertical mixing of the tropical atmosphere makes it difficult for the network sites that are mostly located on remote islands to detect signals from terrestrial $\mathrm{CH}_{4}$ sources. A further limitation is the 5-week lag used in CarbonTracker's EnKF (Ensemble Kalman Filter) scheme that cuts off transport of signals that are transported to remote observing sites.

Note that an additional diagnostic of posterior emissions is the posterior error covariance and its difference from the 
prior covariance. If there are no observations to constrain the posterior estimates, then the posterior error covariance will be unchanged from the prior error covariance. While the posterior error covariance is a very useful diagnostic of the error reduction coming from observations, it is less useful as an indicator of the absolute accuracy of the estimated emissions because the accuracy of the prior estimates is ultimately not very well known, and there are transport errors that cannot be adequately accounted for.

\section{Results}

\subsection{The high northern latitudes}

Here the high northern latitudes are an aggregation of the Transcom 3 regions boreal North America, boreal Eurasia and Europe. This spatial division is somewhat awkward since some of Europe lies south of what could be considered high northern latitudes. We divide Europe into a northern section that lies poleward of $47^{\circ} \mathrm{N}$, and a southern section that is south of $47^{\circ} \mathrm{N}$, where this latitude is chosen to roughly correspond with the southern extents of boreal North American and boreal Eurasian source regions. The prior anthropogenic emissions suggest that $\sim 34 \mathrm{TgCH}_{4} \mathrm{yr}^{-1}$ is emitted from northern Europe, while $\sim 15 \mathrm{TgCH}_{4} \mathrm{yr}^{-1}$ is emitted from southern Europe. Emissions from wetlands are much larger in the northern Europe than in the south.

The 10-year average posterior aggregated flux for the high northern latitudes is $81 \pm 7 \mathrm{Tg} \mathrm{CH}_{4} \mathrm{yr}^{-1}$, a decrease of a little over $12 \mathrm{Tg} \mathrm{CH}_{4} \mathrm{yr}^{-1}$ from the prior aggregated flux. Note that due to the use of a 5-week assimilation window, the uncertainty estimate does not include temporal error covariance over timescales longer than this period and it should therefore be regarded as the best estimate possible for the long term error covariance given the limitations of the current assimilation scheme. The inversion suggests that most of this decrease is a reduction in natural wetland emissions ( $8 \mathrm{Tg} \mathrm{CH}_{4} \mathrm{yr}^{-1}$ ) with the remaining amount coming from fugitive fossil fuel emissions, although the portioning between these sources is strongly influenced by the prior distributions and relative locations of observation sites. Although the observing network could still be considered sparse at high northern latitudes, the number of existing sites is sufficient to reduce uncertainty by over $75 \%$ from the prior uncertainty. The total posterior flux ranges from $78 \mathrm{Tg} \mathrm{CH}_{4} \mathrm{yr}^{-1}$ in 2004 to just under $86 \mathrm{Tg} \mathrm{CH}_{4} \mathrm{yr}^{-1}$ in 2007 (Fig. 12), a year that saw record warm temperatures throughout much of boreal North America and boreal Eurasia, as well as extremely low sea ice coverage (Stroeve et al., 2008).

Annual average methane emissions at high northern latitudes are approximately evenly divided between fugitive emissions from fossil fuels, agriculture and waste (coming mostly from Europe) and natural wetlands. As a whole, emissions from fossil fuel leakage are slightly decreased

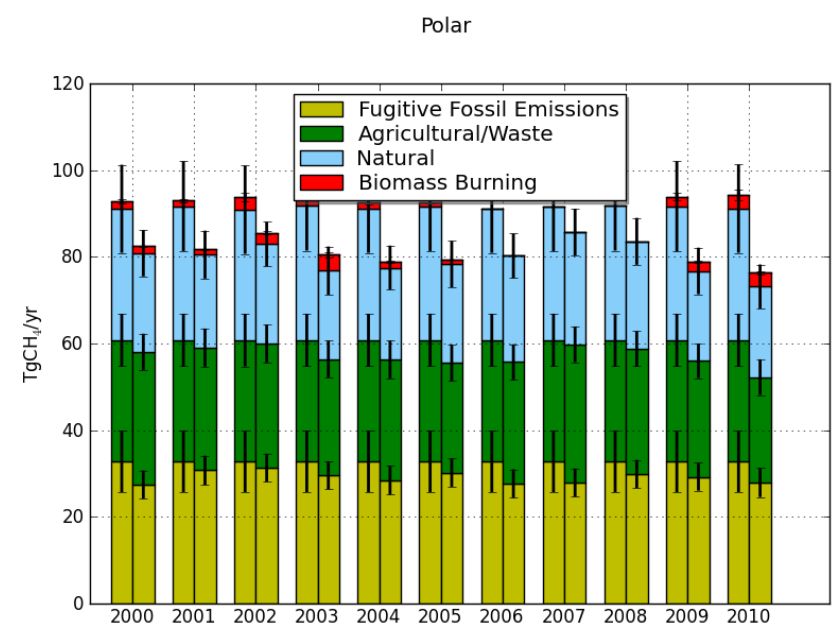

Figure 12. The contribution to the high northern latitude total $\mathrm{CH}_{4}$ flux from each category of emissions with 1-s error estimates. For each pair of histogram bars, the prior flux estimates are shown on the left and the posterior estimates on the right. Note that, except for emissions from fires, the prior flux estimates are constant for each year. The units are $\mathrm{Tg} \mathrm{CH}_{4} \mathrm{yr}^{-1}$. The average estimated uncertainty on the total emissions is $7.5 \mathrm{Tg} \mathrm{CH}_{4} \mathrm{yr}^{-1}$.

relative to prior estimates by about $4 \mathrm{TgCH}_{4} \mathrm{yr}^{-1}$ from $33 \mathrm{TgCH}_{4} \mathrm{yr}^{-1}$, a change that is slightly larger than the posterior estimated uncertainty, $3 \mathrm{TgCH}_{4} \mathrm{yr}^{-1}$. Note that $\sim 4 \mathrm{TgCH}_{4} \mathrm{yr}^{-1}$ of the $29 \mathrm{TgCH}_{4} \mathrm{yr}^{-1}$ due to fugitive fossil fuel emissions comes from southern Europe. Emissions from agriculture and waste are unchanged. Annual average wetland emissions over the high northern latitudes are reduced by $26 \%$ from a prior of $31 \mathrm{Tg} \mathrm{CH}_{4} \mathrm{yr}^{-1}$ to about $23 \mathrm{TgCH}_{4} \mathrm{yr}^{-1}$, a difference that is larger than the average estimated of $\sim 5 \mathrm{TgCH}_{4} \mathrm{yr}^{-1}$. This result is in agreement with previous studies (e.g., Chen and Prinn, 2006; Bergamaschi et al., 2007; Spahni et al., 2011). Our results do not agree with the emission estimates of Bloom et al. (2010). They find that only $2 \%$ of global wetland emissions come from the high northern latitudes, while we find closer to $10 \%$. On the other hand our results agree within uncertainties with the estimates of McGuire et al. (2012) based on flux measurements. They find a source of $25 \mathrm{Tg} \mathrm{CH}_{4} \mathrm{yr}^{-1}$ from Arctic tundra wetlands with uncertainty ranging from 10.7 to 38.7 $\mathrm{Tg} \mathrm{CH}_{4} \mathrm{yr}^{-1}$. Applying the same spatial filter for their Arctic tundra region, CarbonTracker- $\mathrm{CH}_{4}$ estimates a somewhat smaller $16 \pm 5 \mathrm{Tg} \mathrm{CH}_{4} \mathrm{yr}^{-1}$. The fact that field studies may be biased towards larger emissions could at least partially account for the lower estimate based on atmospheric observations. On the other hand, we cannot rule out the possibility that the TM5 representation of the polar atmosphere is too stable, leading to an accumulation of methane emissions in the lower atmosphere the inversion will therefore reduce emissions in order to match observations. 
The estimated flux anomaly during 2007 is $4.4 \pm 3.8 \mathrm{Tg} \mathrm{CH}_{4}$ with a maximum summer anomaly of $2.3 \mathrm{Tg} \mathrm{CH}_{4}$ in July (Fig. 13). If the anomaly is calculated by subtracting the 2000-2006 average annual flux the estimated 2007 anomaly is $5.3 \mathrm{TgCH}_{4}$, similar to the result found by Bousquet et al. (2011). The results of Bergamaschi et al. (2013) also seem to be consistent with these estimates (1.2-3.2 $\left.\mathrm{TgCH}_{4}\right)$. Based on zonal average analysis of network observations, Dlugokencky et al. (2009) pointed out that in 2007 the global increase of methane was equal to about a $23 \mathrm{Tg} \mathrm{CH}_{4}$ imbalance between emissions and sinks, and that the largest increases in $\mathrm{CH}_{4}$ growth occurred in the Arctic (> $15 \mathrm{ppb} \mathrm{yr}^{-1}$ ). This does not necessarily imply that the largest surface flux anomalies occurred at high northern latitudes. Bousquet et al. (2011) noted that the relatively weak vertical mixing characteristic of polar latitudes results in a larger response in atmospheric $\mathrm{CH}_{4}$ mole fractions to anomalous surface emissions than at tropical latitudes where strong vertical mixing rapidly lofts surface emissions through a deep atmospheric column. Transport models therefore can play an important role in helping to untangle surface flux signals from variability in atmospheric transport processes, although care must to be taken to also consider possible biases in modeled transport.

In 2008, the flux anomalies dropped to $2.4 \mathrm{Tg} \mathrm{CH}_{4}$, or $3 \mathrm{Tg} \mathrm{CH}_{4}$ if the anomaly is calculated by subtracting the average annual flux over 2000-2006, as was done by Bousquet et al. (2011) who obtained $2 \mathrm{TgCH}_{4}$ for their INV1 that is similar to CarbonTracker- $\mathrm{CH}_{4}$, but $-3 \mathrm{Tg} \mathrm{CH}_{4} \mathrm{yr}^{-1}$ using their higher spatial resolution variational inversion (INV2). As pointed out by Dlugokencky et al. (2009), both 2007 and 2008 were warm with higher than normal precipitation. Posterior covariance estimates support the independence of estimates for boreal North America and boreal Eurasia since the covariance between these two regions is small; however, it is difficult to accurately relate variability in observed temperature and moisture anomalies with variability in estimated emissions because of the sparseness of the surface observation sites.

For the high northern latitudes CarbonTracker- $\mathrm{CH}_{4}$ is able to distinguish between different $\mathrm{CH}_{4}$ source processes and regions. Wetlands may be distinguished from anthropogenic sources because of the spatial separation of prior flux constraints; many high northern latitude wetland complexes are located in relatively sparsely populated areas, while fossil fuel and agricultural and waste emissions are distributed mainly in populated areas of Europe (although the Western Siberian Lowlands is also a region of intensive fossil fuel production). Ocean methane fluxes are thought to be small compared to terrestrial fluxes, and northern Eurasia and boreal North America are separated by the North Pacific Ocean. Furthermore, the stronger zonal and weaker vertical transport characteristic of the high latitudes helps to transport flux information to network sites. Both Europe and boreal North America are at least partially constrained by surface network
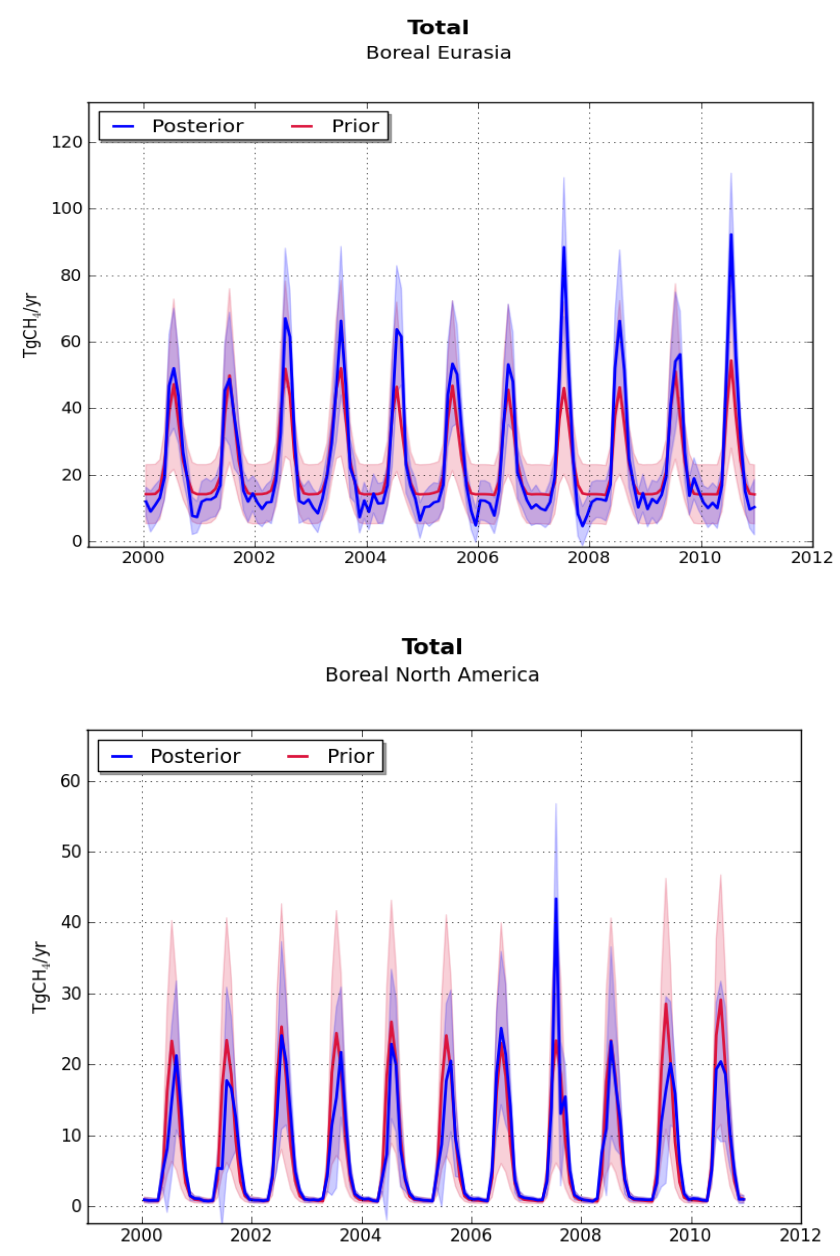

Figure 13. Time variation of the prior and estimated $\mathrm{CH}_{4}$ emissions. Prior estimates are shown in red, and posterior flux estimates are shown in blue. Note that only the biomass burning prior emission estimates vary from year to year; other prior estimates are constant. $1 \sigma$ uncertainty bounds are shown as light red (prior) and light blue (post-assimilation) shaded areas. Note that microbial sources of methane, such as wetlands and agriculture, are temperaturesensitive and therefore tend to be largest during summer. Units are $\mathrm{Tg} \mathrm{CH}_{4} \mathrm{yr}^{-1}$.

sites, and although boreal Eurasia is not adequately covered by network sites, a number of sites exist downwind of it (Shemya, Barrow and Cold Bay). For Europe, average trajectory calculations suggest that a large region of wetlands in eastern Scandinavia and northwestern Russia is constrained by Pallas, Finland. Other sites help to constrain the anthropogenic sources from the rest of Europe.

For boreal North America, prior flux emissions from fossil fuels and agriculture and waste form an insignificant part of total methane emissions. This is not the case for Europe for which emissions are more evenly divided between anthropogenic and wetland emissions. Note that about $40 \%$ of the agricultural emissions and $22 \%$ of the fossil fuel emissions are from southern Europe. Prior emission estimates 
from natural sources for Europe, the majority of which lie in northern Europe, are about $45 \mathrm{Tg} \mathrm{CH}_{4} \mathrm{yr}^{-1}$ during the summer months while the $11 \mathrm{yr}$ average posterior summer estimate is about $13 \mathrm{TgCH}_{4} \mathrm{yr}^{-1}$, a large reduction. The uncertainty estimates, however, only decrease by at most $15 \%$ implying that the source categories are not strongly constrained by observations. Boreal Eurasian summertime wetland emissions are increased relative to the prior flux estimates from $26 \mathrm{Tg} \mathrm{CH}_{4} \mathrm{yr}^{-1}$ to $37 \mathrm{Tg} \mathrm{CH}_{4} \mathrm{yr}^{-1}$, and posterior uncertainties decrease from prior uncertainties by $\sim 20$ $25 \%$. For boreal North America, the average posterior summer wetland flux is only slightly below the prior flux estimate (about $19 \mathrm{Tg} \mathrm{CH}_{4} \mathrm{yr}^{-1}$ compared to about $16 \mathrm{Tg} \mathrm{CH}_{4} \mathrm{yr}^{-1}$, a difference that is within the summer average posterior estimated uncertainty of $\sim 10 \mathrm{Tg} \mathrm{CH}_{4} \mathrm{yr}^{-1}$ ). The redistribution of emissions from Europe to northern Eurasia was found by Chen and Prinn (2006) to be sensitive to the choice of sites used in the inversion, however, our results indicate that the observations imply that while prior emissions are too high for Europe, larger emissions are still needed elsewhere to match the meridional distribution of observed methane. Bergamaschi et al. (2005) also found decreased emissions for Europe relative to prior estimates, but interestingly, their inversion also reduced high-latitude emissions from prior estimates for other high latitude source regions as well. During the winter months, when biogenic emissions are low, prior estimates are decreased by the inversion for both boreal Eurasia $(-20 \%)$ and Europe $(-8 \%)$ and relatively unchanged for boreal North America. The small change in winter European emissions supports the conclusion that prior wetland emissions for Europe are indeed overestimated. Note that prior emissions for wetland emissions from northern Europe are about equal to fugitive emissions from fossil fuels.

High latitude emissions of $\mathrm{CH}_{4}$ from agriculture and waste are significant only for Europe, and estimated fluxes are unchanged from prior estimates. Fugitive emissions of $\mathrm{CH}_{4}$ from fossil fuel production are reduced from prior estimates for Europe and boreal Eurasia by $2 \mathrm{Tg} \mathrm{CH}_{4} \mathrm{yr}^{-1}$ for each region; from $21 \pm 4 \mathrm{TgCH}_{4} \mathrm{yr}^{-1}$ and $12 \pm 2 \mathrm{Tg} \mathrm{CH}_{4} \mathrm{yr}^{-1}$. Reductions in uncertainty are fairly large for Europe, $\sim 35 \%$, and about $\sim 32 \%$ for boreal Eurasia. For boreal North America, prior estimates of fossil fuel emissions of $\mathrm{CH}_{4}$ are very small $\left(<1 \mathrm{Tg} \mathrm{CH}_{4} \mathrm{yr}^{-1}\right)$, and it should be noted that the tar sand production areas are in the temperate North American TransCom 3 source region rather than boreal North America.

Significant natural $\mathrm{CH}_{4}$ emissions have recently been proposed for the high northern latitudes. Walter et al. (2007) estimated that in addition to emissions from high northern latitude wetlands $\left(31 \mathrm{Tg} \mathrm{CH}_{4} \mathrm{yr}^{-1}\right.$ for the CarbonTracker$\mathrm{CH}_{4}$ prior), ebullition from arctic lakes could add an additional $24 \pm 10 \mathrm{TgCH}_{4} \mathrm{yr}^{-1}$. In addition to organic rich sediments and subsea permafrost, $\mathrm{CH}_{4}$ is stored in ice hydrates forming at the low temperatures and high pressures in sediments at the bottom of the Arctic Ocean and subsea permafrost, and below terrestrial permafrost as well. Rela- tively shallow waters make it possible for bubbles to transport methane directly and rapidly to the atmosphere. The estimates of Shakhova et al. (2013) estimate the size of the source from subsea permafrost from the East Siberian shelf alone to be $\sim 17 \mathrm{Tg} \mathrm{CH}_{4} \mathrm{yr}^{-1}$, although observational records are currently insufficient to establish whether these emissions are changing over time. Walter et al. (2012) have proposed that a similar process may also occur on land as permafrost thaws and glaciers melt. Total natural emissions including all of these processes approaches $65 \mathrm{Tg} \mathrm{CH}_{4} \mathrm{yr}^{-1}$, an amount that significantly exceeds both the average prior and posterior annual natural emissions for CarbonTracker- $\mathrm{CH}_{4}$ ( 31 and $23 \mathrm{Tg} \mathrm{CH}_{4} \mathrm{yr}^{-1}$ ). Since the average total posterior CarbonTracker- $\mathrm{CH}_{4}$ high northern latitude emissions is $\sim 81 \mathrm{TgCH}_{4} \mathrm{yr}^{-1}$, accommodation of a $65 \mathrm{Tg} \mathrm{CH}_{4} \mathrm{yr}^{-1}$ natural source would have to come at the expense of fossil fuel and agriculture/waste sources (average total CarbonTracker- $\mathrm{CH}_{4}$ posterior of $\sim 57 \mathrm{Tg} \mathrm{CH}_{4} \mathrm{yr}^{-1}$, with about $12 \mathrm{Tg} \mathrm{CH}_{4} \mathrm{yr}^{-1}$ emitted from southern Europe), which would need to be reduced by about $75 \%$.

The estimated mass of carbon thought to be frozen in Arctic permafrost down to $20 \mathrm{~m}$ is estimated to be $\sim 1700 \mathrm{PgC}$ $\left(\mathrm{Pg}=10^{15} \mathrm{~g}\right)$ (Tarnocai et al., 2009), significantly more carbon than is currently in the atmosphere $(\sim 830 \mathrm{PgC})$ and over 3 times what has already been emitted to the atmosphere from fossil fuel use since pre-industrial times. As the Arctic warms and permafrost thaws, this ancient carbon may be mobilized to the atmosphere and a small fraction $(\sim 3 \%)$ may be emitted as $\mathrm{CH}_{4}$ (Schuur et al., 2011). Recent studies suggest that permafrost carbon will begin to enter the atmosphere during this century (e.g., Schaefer et al., 2010; Harden et al., 2012; Melton et al., 2013; Frolking et al., 2011). Harden et al. (2012) predict that $215-380 \mathrm{PgC}$ will thaw by 2100 . Their assessment of the carbon balance of Arctic tundra based on flux observations McGuire et al. (2012) found that between the 1990s and 2000s emissions of $\mathrm{CH}_{4}$ doubled (from 13 to $26 \mathrm{Tg} \mathrm{CH}_{4} \mathrm{yr}^{-1}$ ), results that are consistent with warmer temperature and longer growing seasons.

Detection of trends in Arctic greenhouse gas emissions is difficult using atmospheric concentration measurements alone because changes are expected to be small in comparison to transport of much larger mid-latitude emissions. Forward and inverse modeling techniques can be helpful because they provide the ability to untangle variability coming from transport from signals associated with local sources. As shown in Fig. 13, posterior CarbonTracker- $\mathrm{CH}_{4}$ emissions do not indicate that there has been a trend in natural high northern latitude emissions over the last decade, although we see strong evidence for substantial inter-annual variability.

\subsection{The Northern Hemisphere mid-latitudes}

For this study, the northern mid-latitudes are composed of the temperate Eurasia and temperate North America Transcom 3 regions (see Fig. 1). The average estimated 
total emissions for the northern mid-latitudes over the period 2000-2010 are greater than prior estimates by about $5 \mathrm{Tg} \mathrm{CH}_{4} \mathrm{yr}^{-1}$, increasing from about $156 \pm 27 \mathrm{Tg} \mathrm{CH}_{4} \mathrm{yr}^{-1}$ to $162 \pm 16 \mathrm{Tg} \mathrm{CH}_{4} \mathrm{yr}^{-1}$. After the tropics, the Northern Hemisphere mid-latitudes emit the most atmospheric $\mathrm{CH}_{4}$. The largest mid-latitude source of $\mathrm{CH}_{4}$ is agriculture and waste, and this source rises from $117 \pm 26 \mathrm{Tg} \mathrm{CH}_{4} \mathrm{yr}^{-1}$ to $119 \pm 15 \mathrm{Tg} \mathrm{CH}_{4} \mathrm{yr}^{-1}$. Natural wetlands are a fairly small contribution to northern mid-latitude emissions, and they are increased from about $9 \pm 3$ to $12 \pm 2 \mathrm{Tg} \mathrm{CH}_{4} \mathrm{yr}^{-1}$. For the northern mid-latitudes as a whole, estimated fossil fuel emissions remain very close to prior estimates at about $31 \pm 3 \mathrm{TgCH}_{4}$

In general, CarbonTracker- $\mathrm{CH}_{4}$ re-distributes prior estimated emissions from temperate Eurasia to North America (Fig. 14). The total prior flux estimates for temperate Eurasia and temperate North America are $124 \pm 22$ and $32 \pm 5 \mathrm{Tg} \mathrm{CH}_{4} \mathrm{yr}^{-1}$, respectively. The average posterior estimates are $114 \pm 15$ and $47 \pm 3 \mathrm{Tg} \mathrm{CH}_{4} \mathrm{yr}^{-1}$. Agriculture and waste emissions from temperate Eurasia are reduced by almost $10 \mathrm{Tg} \mathrm{CH}_{4} \mathrm{yr}^{-1}(\sim 9 \%)$. Fugitive fossil fuel emissions for temperate North America increase by $\sim 9 \%(6.7 \pm 1.5$ to $8 \pm 1 \mathrm{TgCH}_{4} \mathrm{yr}^{-1}$ ), agriculture and waste emission increase by $53 \%\left(21 \pm 4\right.$ to $\left.32 \pm 3 \mathrm{TgCH}_{4} \mathrm{yr}^{-1}\right)$, and natural emissions increase by $66 \%\left(4.5 \pm 1 \mathrm{TgCH}_{4} \mathrm{yr}^{-1}\right.$ to $\left.7.5 \pm 1 \mathrm{Tg} \mathrm{CH}_{4} \mathrm{yr}^{-1}\right)$. Posterior uncertainties for both regions decrease from prior uncertainty by about $30 \%$.

In this version of CarbonTracker- $\mathrm{CH}_{4}$, we used constant anthropogenic emissions representative of the year 2000 from the EDGAR v3.2 FT database as priors. A more recent version of EDGAR (version 4.2, (European Commission, JRC, 2009) reports that global anthropogenic emissions of methane significantly increased over the last decade, from $309 \mathrm{Tg} \mathrm{CH}_{4} \mathrm{yr}^{-1}$ in 2000 to $364 \mathrm{Tg} \mathrm{CH}_{4} \mathrm{yr}^{-1}$ by 2008 (an increase of about $18 \%$ ). Most of this increase $(37 \mathrm{Tg}$ $\mathrm{CH}_{4} \mathrm{yr}^{-1}$ ) is estimated to have occurred between 2000 and 2006 according to EDGAR. As we show in Fig. 8, the observed global total $\mathrm{CH}_{4}$ does not change much between 2000 and 2005. Bousquet et al. (2006) proposed that increased anthropogenic emissions were balanced by decreases in wetland emissions for the early 2000s CarbonTracker- $\mathrm{CH}_{4}$ is constrained using a time-invariant prior, and because it must follow the observed global growth rate that flat at least until 2006, it does not find trends in either total anthropogenic or natural emissions.

After 2006 the observed global annual mean $\mathrm{CH}_{4}$ abundance increased $\sim 25 \mathrm{ppb}$ by 2010 , equivalent to additional emissions of $\sim 70 \mathrm{TgCH}_{4}$ over 4 years $\left(18 \mathrm{TgCH}_{4} \mathrm{yr}^{-1}\right)$ if mixed uniformly throughout the atmosphere. As discussed in Sect. 3.3, CarbonTracker- $\mathrm{CH}_{4}$ follows the global growth rate closely. The average total emissions from 2000 to 2006 are $\sim 514 \pm 22 \mathrm{TgCH}_{4}$, but after 2006 it is $530 \pm 22 \mathrm{Tg} \mathrm{CH}_{4} \mathrm{yr}^{-1}$, an amount that is in approximate agreement with the change in total emissions implied by observations. CarbonTracker- $\mathrm{CH}_{4}$ allocates much of this in-
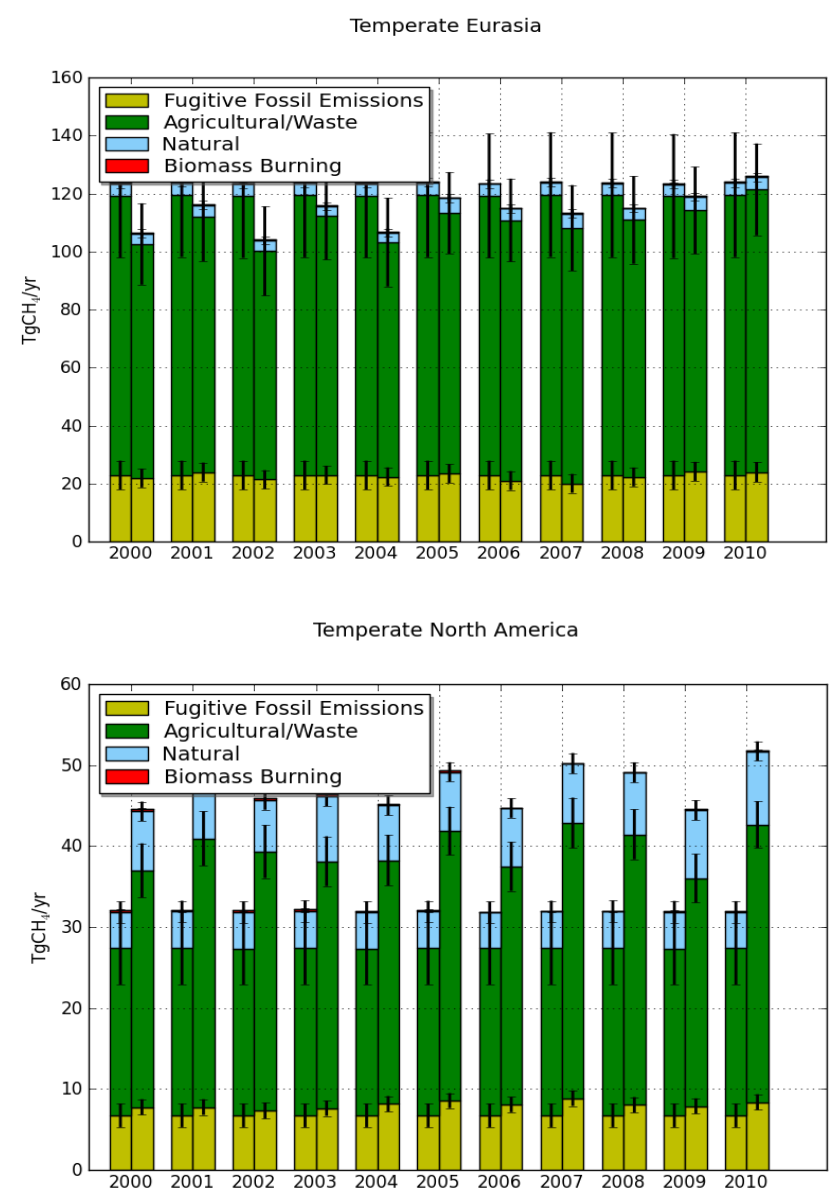

Figure 14. The contribution to the total $\mathrm{CH}_{4}$ flux from each category of emissions with 1-s error bars for temperate Eurasia (top) and temperate North America (bottom). Prior flux estimates are on the left and posterior estimates on the right for each set pair of bars. Note that, except for emissions from fires, the prior flux estimates are constant for each year. Units are $\mathrm{Tg} \mathrm{CH}_{4} \mathrm{yr}^{-1}$. The total 1-s errors for all emission categories are $15.3 \mathrm{Tg} \mathrm{CH}_{4} \mathrm{yr}^{-1}$ and 3.5 $\mathrm{Tg} \mathrm{CH}_{4} \mathrm{yr}^{-1}$ for temperate Eurasia and temperate North America respectively.

crease to anthropogenic sources. Average global total anthropogenic emissions are $316 \pm 18 \mathrm{Tg} \mathrm{CH}_{4} \mathrm{yr}^{-1}$ for 2000 to 2005 , increasing to $325 \pm 18 \mathrm{Tg} \mathrm{CH}_{4} \mathrm{yr}^{-1}$ for 2006 to 2010 , a number that is roughly consistent with the constant anthropogenic prior inversions of Bergamaschi et al. (2013). For the period 2000 to 2005 , the estimated total natural emissions are $198 \pm 12 \mathrm{Tg} \mathrm{CH}_{4} \mathrm{yr}^{-1}$, increasing to $204 \pm 12 \mathrm{Tg} \mathrm{CH}_{4} \mathrm{yr}^{-1}$ from 2006 to 2010. CarbonTracker- $\mathrm{CH}_{4}$ assigns the post2005 estimated increases in anthropogenic emissions to the populated northern temperate latitudes, while the bulk of the global increase in natural emissions is assigned to the tropics.

The EDGAR emission data imply that anthropogenic emissions of $\mathrm{CH}_{4}$ grew rapidly over the last decade, with significant growth occurring between 2000 and 2005, a time when the observed growth rate does not support an 
upward trend in emissions. Could decreased emissions from wetlands have canceled out this increase as Bousquet et al. (2006) proposed? More recent work by Bergamaschi et al. (2013) suggests a large role for anthropogenic emissions, while Houweling et al. (2013) find that a mixture of anthropogenic and tropical wetland sources are responsible for the increase since 2006. Although the sparseness of the observational network makes it impossible to rule this scenario out, the observations and the spatial constraint they supply to the inversion do not suggest that there was a trend in wetland emissions over the first half of the decade, although there certainly was inter-annual variability. On the other hand, this result cannot be reconciled with bottom-up estimates of increasing anthropogenic emissions over this period. From 2006 through 2010, estimated emissions increased by $\sim 15 \mathrm{TgCH}_{4} \mathrm{yr}^{-1}$, slightly less than the $18 \mathrm{Tg} \mathrm{CH}_{4} \mathrm{yr}^{-1}$ estimated by EDGAR for this period, and with considerable inter-annual variability. CarbonTracker$\mathrm{CH}_{4}$ divides this growth between anthropogenic and natural emissions in proportion to their contribution to the prior global atmospheric $\mathrm{CH}_{4}$ budget ( $\sim 60 \%$ anthropogenic and $\sim 40 \%$ natural). Although it is likely that both anthropogenic and natural emissions have been increasing since 2006, this latter fact may also be interpreted as evidence of the inability of the observational network to discriminate between these categories of sources due to insufficient spatial coverage at lower latitudes. It is possible that the use of observed isotopic composition of $\mathrm{CH}_{4}$ could help to distinguish different sources (e.g., Miller et al., 2002). Uncertainty reductions are substantial for the global totals of both natural and anthropogenic emissions, $\sim 66 \%$ each, and this suggests that observational constraints are consistent with the prior allocation of emissions between natural and anthropogenic processes, but does not rule out the possibility that the network cannot discriminate between the two. Bergamaschi et al. (2013) have also suggested that the increases in anthropogenic emissions from EDGAR are likely too high, especially estimates of emissions from Chinese coal production.

Anthropogenic emissions from Asia are thought to have been increasing steeply in recent years. EDGAR v4.2 emissions data set estimates that total anthropogenic emissions from China increased from about $50 \mathrm{Tg} \mathrm{CH}_{4} \mathrm{yr}^{-1}$ in 2000 to over $73 \mathrm{Tg} \mathrm{CH}_{4} \mathrm{yr}^{-1}$ in 2008, an increase of almost $50 \%$. CarbonTracker- $\mathrm{CH}_{4}$ does not show a steady upward trend in emissions from temperate Asia, but there is a $5 \mathrm{Tg} \mathrm{CH}_{4} \mathrm{yr}^{-1}$ increase between the average of the first and last 5 years, a change that is well within the estimated uncertainty for this region of $15 \mathrm{TgCH}_{4} \mathrm{yr}^{-1}$. This is consistent with the $\sim 5 \mathrm{Tg} \mathrm{CH}_{4} \mathrm{yr}^{-1}$ increase in anthropogenic emissions from China between 2003 and 2008 found by Bergamaschi et al. (2013). For temperate North America, there does not appear to be much change over the decade in total estimated emissions; however, fugitive emissions from fossil fuel production in temperate North America show significant increases from prior emissions during winter months, when biogenic emissions are smallest (Fig. 15). By the end of the decade, winter fossil fuel emissions from temperate North America end up higher than prior flux estimates by about $4 \mathrm{Tg} \mathrm{CH}_{4} \mathrm{yr}^{-1}$, exceeding the estimated uncertainty of $\sim 3 \mathrm{Tg} \mathrm{CH}_{4} \mathrm{yr}^{-1}$. Due to large variability of biogenic emissions, it is difficult to see evidence of this change during the warmer seasons, and the variability also may mask evidence of increasing fossil fuel emissions in the total estimated emissions. It is interesting to note that, as shown in Table 1, many of the sites with the largest residuals are located near potential sources of fugitive emissions from fossil fuel use. An example is SGP (the Southern Great Plains site) located in northern Oklahoma. Figure 16 shows that it is increasingly difficult over time for the inversion to fit this site, possibly due to increasing emissions from fossil fuel production nearby and in northern Texas. This feature is qualitatively consistent with the results of Miller et al. (2013), who calculated larger than predicted emissions of $\mathrm{CH}_{4}$ related to fossil fuel extraction in this part of the USA, although they also acknowledge a possible role for emissions from livestock. The recent expansion of oil and gas production is not included in the prior used for CarbonTracker- $\mathrm{CH}_{4}$, and the more recent EDGAR4.2 emission product has more emissions in North America than the prior we used here. Petron et al. (2012) have recently suggested that leakage from fossil fuel production in Colorado's Denver-Julesburg Basin may be several times larger that estimated by state and local inventories. Karion et al. (2013) have recently shown that emissions from a gas field in Utah may be much higher that previous estimates as well.

\subsection{The tropics}

Tropical emissions are difficult to constrain because of the sparse distribution of atmospheric observations, but also due to the tendency of the tropical atmosphere to rapidly mix surface signals throughout a deep atmospheric column. Many of the observation sites in tropical latitudes are located on islands where they sample marine air from higher latitudes. Ascension Island, for example often sees air from the South Atlantic, rather than air transported westward from tropical Africa. Although the site located in the Seychelles site sometimes sees air from southern Asia, often it sees air transported from the southern Indian Ocean. In particular, it is difficult to see how the current observational network can independently constrain tropical Asia and tropical Africa. On the other hand, Pacific Ocean sites may make it possible to discriminate between tropical America and Asia.

In agreement with the results found by other studies (e.g., Houweling et al., 1999; Bergamaschi et al., 2007; Mikaloff-Fletcher et al., 2004a, b; Houweling et al., 2013), CarbonTracker- $\mathrm{CH}_{4}$ increases tropical emissions relative to prior estimates. The average total prior emission is $132 \pm 18 \mathrm{Tg} \mathrm{CH}_{4} \mathrm{yr}^{-1}$ and the posterior total is about $157 \pm 11 \mathrm{Tg} \mathrm{CH}_{4} \mathrm{yr}^{-1}$, an increase of $19 \%$. The estimated 
Fossil Fuel

Temperate North America, DJF

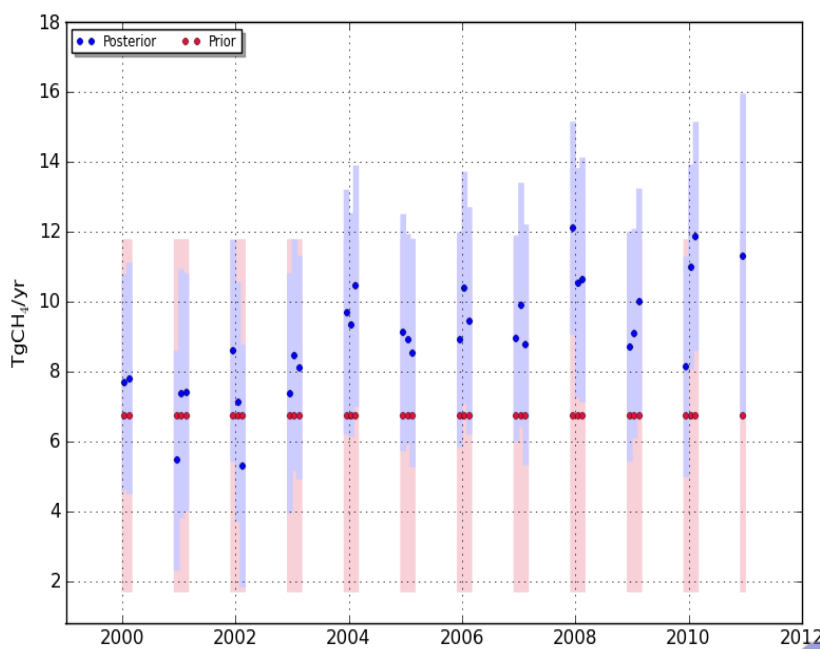

Figure 15. Time variation of the estimated $\mathrm{CH}_{4}$ emissions from temperate North America for winter. Prior flux estimates are shown in red, and posterior flux estimates are shown in blue. 1- $\sigma$ uncertainty bounds are shown as light red (prior) and light blue (posterior) shaded areas. Units are $\mathrm{TgCH}_{4} \mathrm{yr}^{-1}$.

uncertainty is $\pm 11 \mathrm{TgCH}_{4} \mathrm{yr}^{-1}$, a decrease from the prior uncertainty of about $39 \%$. This suggests that the observations are able to add some information about tropical emissions to the inversion. Most of the adjustment in emissions goes to wetlands (an increase of $31 \%$ from $\sim 65 \mathrm{TgCH}_{4} \mathrm{yr}^{-1}$ to $\sim 84 \mathrm{Tg} \mathrm{CH}_{4} \mathrm{yr}^{-1}$, with a decrease in uncertainty from 14 to $8 \mathrm{TgCH}_{4} \mathrm{yr}^{-1}$, or $57 \%$ ). Posterior anthropogenic emissions are essentially unchanged from priors with posterior emissions of $49 \mathrm{Tg} \mathrm{CH}_{4} \mathrm{yr}^{-1}$ for agriculture and waste, and $\sim 7.5 \mathrm{Tg} \mathrm{CH}_{4} \mathrm{yr}^{-1}$ for fossil fuel emissions, with the uncertainty in total anthropogenic emissions decreasing from $11 \mathrm{TgCH}_{4} \mathrm{yr}^{-1}$ to about $7 \mathrm{TgCH}_{4} \mathrm{yr}^{-1}$. CASA-GFED prior flux estimates for biomass burning are increased from about $10 \mathrm{Tg} \mathrm{CH}_{4} \mathrm{yr}^{-1}$ to $11 \mathrm{Tg} \mathrm{CH}_{4} \mathrm{yr}^{-1}$.

Interestingly, the estimated increases in decadalaverage emission from tropical wetlands are not evenly distributed among the tropical regions of South America, Africa and Asia. Changes are largest for South America, increasing from a prior of about $19 \pm 4 \mathrm{Tg} \mathrm{CH}_{4} \mathrm{yr}^{-1} \quad$ to almost $32 \pm 4 \mathrm{Tg} \mathrm{CH}_{4} \mathrm{yr}^{-1}$ $(+68 \%)$. For Africa, posterior emissions increase from $17 \pm 4 \mathrm{Tg} \mathrm{CH}_{4} \mathrm{yr}^{-1}$ to $21 \pm 4 \mathrm{Tg} \mathrm{CH}_{4} \mathrm{yr}^{-1}(+24 \%)$ and for Asia, $29 \pm 6 \mathrm{Tg} \mathrm{CH}_{4} \mathrm{yr}^{-1}$ to $35 \pm 6 \mathrm{Tg} \mathrm{CH}_{4} \mathrm{yr}^{-1}$ (+21\%). The estimates from CarbonTracker- $\mathrm{CH}_{4}$ compare well with Melack et al. (2004), who estimate that the Amazon Basin emits about $29 \mathrm{TgCH}_{4} \mathrm{yr}^{-1}$ using a combination of field studies and satellite observations of wetland extent. Estimated emissions from anthropogenic sources remain very close to prior estimates for all tropical regions, and

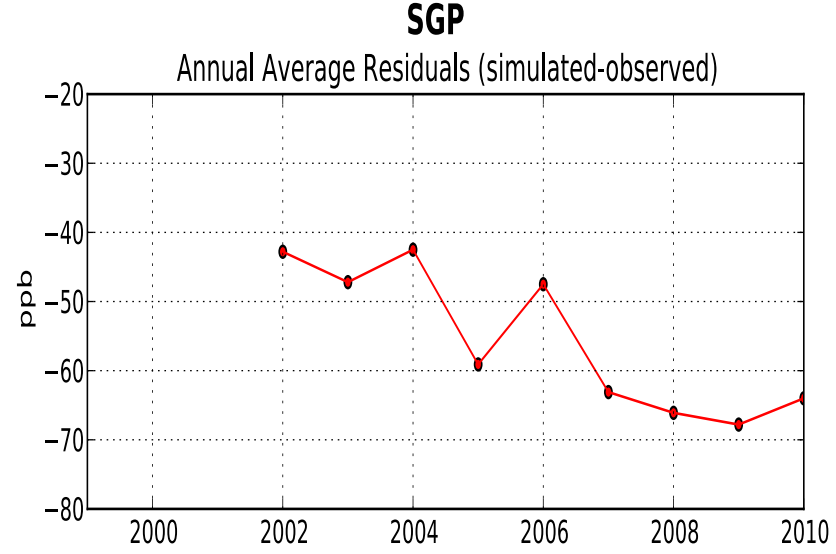

Figure 16. Time series of residuals (the difference between the posterior and measured mole fractions). Note that the prior is constant over the length of the inversion, and the trend in the residuals can be interpreted to mean that it is increasingly difficult to fit this site over time. Units are $10^{-9} \mathrm{~mol} \mathrm{~mol}^{-1}$ of $\mathrm{CH}_{4}(\mathrm{ppb})$.

this is also the case for biomass burning. For all tropical regions, the posterior uncertainty is only slightly reduced with respect to the prior uncertainty, generally less than $15 \%$, and the high posterior correlations between these regions make it difficult to have confidence that the inversion is able to constrain information about these regions.

Although observations indicate inter-annual variability in the $\mathrm{CH}_{4}$ growth rate in the tropical marine boundary layer, CarbonTracker- $\mathrm{CH}_{4}$ is not able to capture this very well as discussed in the previous section on evaluation. Figure 17 shows both the increase in posterior $\mathrm{CH}_{4}$ emission estimates from the prior, as well the inter-annual variability of the estimates. Total biogenic emissions (e.g., agriculture/waste and wetlands) were larger than normal during 2007 and 2008 in agreement with the analysis of Dlugokencky et al. (2009), who noted that both of these years were relatively wet in the tropics. Wet years are also years with lower fire emissions and the posterior emissions of CarbonTracker- $\mathrm{CH}_{4}$ show a significant anti-correlation of fire and wetland emissions as shown in Fig. 18, although the estimated uncertainties on the emission anomalies are quite large.

Increases in tropical emissions for 2007 and 2008 are also found by Bergamaschi et al. (2013) although they show interesting differences between their inversions that used spacebased observations and those using only surface observations. Houweling et al. (2013) showed that use of spacebased observations with a bias correction that is fixed using independent data rather than estimated by the inversion results in a re-distribution of emissions from the extra-tropical Northern Hemisphere to the tropics by $\sim 50 \mathrm{Tg} \mathrm{CH}_{4} \mathrm{yr}^{-1}$. Their tropical emissions over 2003 to 2010 range from 380 to $450 \mathrm{Tg} \mathrm{CH}_{4} \mathrm{yr}^{-1}$, much higher than the values obtained by this study, although the latitude range of their tropics is not clear. CarbonTracker- $\mathrm{CH}_{4}$ values are similar to Houweling et 


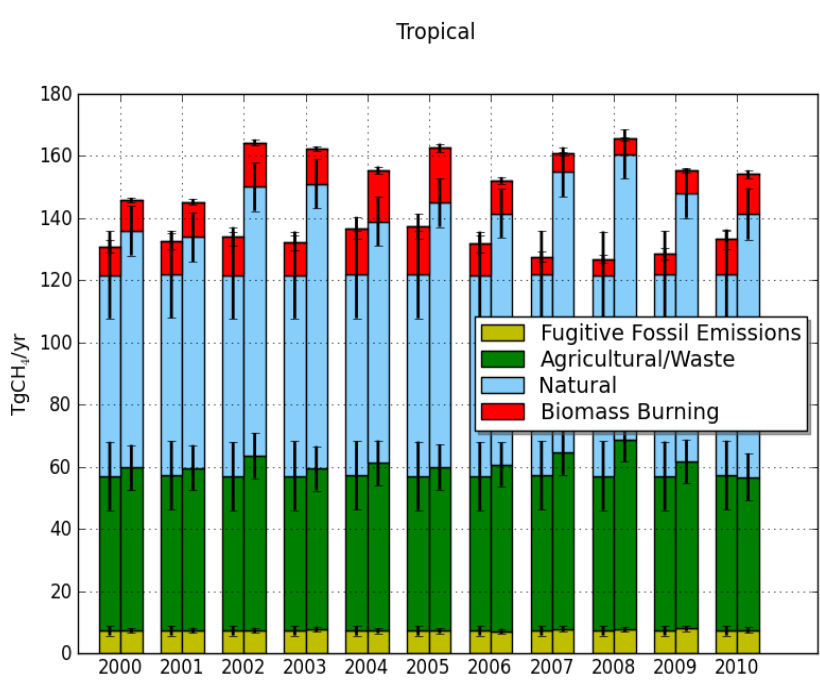

Figure 17. The contribution to the total $\mathrm{CH}_{4}$ flux from each category of emissions with 1-s error bars for the tropics (tropical South America, tropical Asia and tropical Africa). For each pair of histogram bars, the prior flux estimates are shown on the left and the posterior estimates on the right. Note that, except for emissions from fires that are very small for these regions, the prior flux estimates are constant for each year. The units are $\mathrm{Tg} \mathrm{CH}_{4} \mathrm{yr}^{-1}$. The average total estimated 1-s error is $10.8 \mathrm{Tg} \mathrm{CH}_{4} \mathrm{yr}^{-1}$.

al. (2013) if we use $30^{\circ} \mathrm{S}-30^{\circ} \mathrm{N}$ as the latitude range of the tropics. In addition, Houweling et al. (2013) note that they estimate larger inter-annual variability in tropical emissions of $\mathrm{CH}_{4}$ using their preferred bias correction methodology. Although this may indicate that the space-based observations are adding significant new information to the inversion, as noted by Houweling et al. (2013), degradation of the instrument occurred after 2005.

In addition to a greatly needed expansion of sites sensitive to the tropical biosphere (e.g., Miller et al., 2007), progress on constraining tropical emissions could be made by increasing the length of the assimilation window, allowing signals to reach existing observation sites from terrestrial tropical source regions, and by using aircraft observations as constraints in the assimilation. Also since CarbonTracker- $\mathrm{CH}_{4}$ seems to miss tropical variability in emissions, it is likely that the growth in global $\mathrm{CH}_{4}$ abundance due to tropical wetlands is greater than the posterior estimates suggest. Comparisons of posterior $\mathrm{CH}_{4}$ profiles with profiles measured aircraft at two sites in Brazil (Fortaleza on the coast, and Santarem in the interior) support both the underestimate of emissions in the priors and the lack of data to revise the priors adequately. This was also pointed out by Beck et al. (2012).

Since setting up and maintaining observation sites in tropical land regions is logistically difficult, coverage may never be adequate in these regions. The hope is that remote sensing observations could provide additional observational constraints, however, the issue of how to identify and quantify

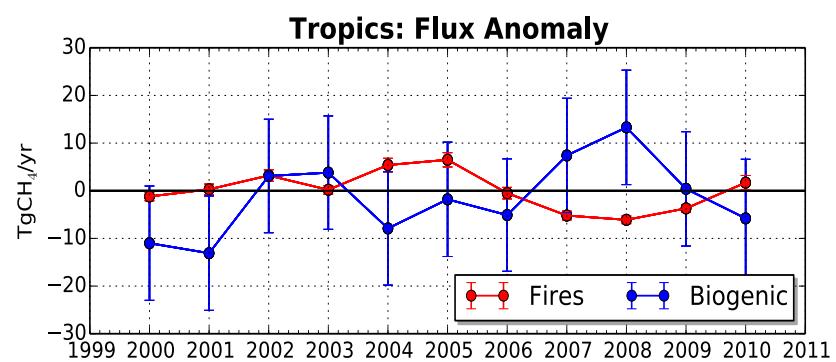

Figure 18. Time variation of estimated total biogenic (wetlands and agriculture/waste) and fire $\mathrm{CH}_{4}$ emission anomalies. Anomalies are calculated with respect to $10 \mathrm{yr}$ average posterior emissions. The units are $\mathrm{TgCH}_{4} \mathrm{yr}^{-1}$. The error bars represent 1-s estimated error bounds on the flux anomalies.

biases in remotely sensed $\mathrm{CH}_{4}$ that are be spatially and temporally coherent is still be an important limitation (Houweling et al., 2013).

\subsection{The Southern Hemisphere mid-latitudes}

Decadal mean $\mathrm{CH}_{4}$ emission estimates from southern temperate latitudes (temperate South America, South Africa and Australia) increase from a prior of $78 \mathrm{TgCH}_{4} \mathrm{yr}^{-1}$ to $91 \mathrm{Tg} \mathrm{CH}_{4} \mathrm{yr}^{-1}$, an increase of about $17 \%$. The aggregated uncertainty estimate decreases from about $12 \mathrm{Tg} \mathrm{CH}_{4} \mathrm{yr}^{-1}$ to $7 \mathrm{Tg} \mathrm{CH}_{4} \mathrm{yr}^{-1}$, a decrease of about $40 \%$. The largest estimated $\mathrm{CH}_{4}$ emissions are from temperate South America $\left(54 \pm 6 \mathrm{Tg} \mathrm{CH}_{4} \mathrm{yr}^{-1}\right)$, followed by temperate South Africa $\left(22 \pm 2 \mathrm{Tg} \mathrm{CH}_{4} \mathrm{yr}^{-1}\right)$ and Australia/New Zealand $\left(15 \pm 2 \mathrm{Tg} \mathrm{CH}_{4} \mathrm{yr}^{-1}\right)$. Annual average flux estimates for the aggregated total emissions, as well as the individual processes are little changed from prior estimates for both temperate southern Africa and Australia/New Zealand. The posterior uncertainty estimates for these regions are essentially unchanged as well, indicating a lack of significant observational constraints for these regions.

On the other hand, aggregated total emissions for temperate South America are adjusted from $43 \pm 7 \mathrm{Tg} \mathrm{CH}_{4} \mathrm{yr}^{-1}$ to $54 \pm 6 \mathrm{Tg} \mathrm{CH}_{4} \mathrm{yr}^{-1}$, although with a relatively small uncertainty reduction of about $9 \%$. The adjustment to $\mathrm{CH}_{4}$ emissions occurs as an increase from natural biogenic sources, since fossil fuel emissions and agriculture/waste prior flux estimates are small for this region. Emissions from natural wetlands increase by $7 \mathrm{Tg} \mathrm{CH}_{4} \mathrm{yr}^{-1}$ over prior estimates, and agriculture and waste by close to $4 \mathrm{Tg} \mathrm{CH}_{4} \mathrm{yr}^{-1}$. The uncertainty reduction for natural wetlands is very small, while uncertainty estimates for agriculture and waste are about $13 \%$ smaller than the priors.

\subsection{The global ocean}

Emissions of $\mathrm{CH}_{4}$ from oceans are thought to make only a small contribution to the atmospheric $\mathrm{CH}_{4}$ budget, with a prior flux estimate in CarbonTracker- $\mathrm{CH}_{4}$ 
of $\sim 15 \pm 13 \mathrm{Tg} \mathrm{CH}_{4} \mathrm{yr}^{-1}$. Posterior estimates are adjusted downwards to $12.6 \mathrm{TgCH}_{4} \mathrm{yr}^{-1}$, a difference that exceeds the posterior uncertainty estimate of about $15 \mathrm{Tg} \mathrm{CH}_{4} \mathrm{yr}^{-1}$. Rhee et al. (2009) have proposed that earlier estimates of the oceanic methane emissions were biased towards supersaturated waters, and that the emissions are much lower, about 0.6-1.2 $\mathrm{Tg} \mathrm{CH}_{4} \mathrm{yr}^{-1}$, a decrease of over a factor of 10. It is therefore possible that future versions of CarbonTracker$\mathrm{CH}_{4}$ will not include estimation of ocean emissions. Note that the ocean source does not include ebullition from methane seeps and subsea permafrost (e.g., Shakhova et al., 2010). The size and variability of emissions from this source are not currently well understood, but since significant flux to the atmosphere can only occur in relatively shallow waters, this source would likely be aliased with terrestrial sources by CarbonTracker- $\mathrm{CH}_{4}$.

\section{Conclusions}

We have created an assimilation system for atmospheric methane, CarbonTracker- $\mathrm{CH}_{4}$ and used it to estimates $\mathrm{CH}_{4}$ emissions during 2000-2010 over large spatial scales. We find that simulated $\mathrm{CH}_{4}$ mole fractions calculated using optimized emissions at each measurement site agree well with observations with an average bias of $-10.4 \mathrm{ppb}$. Also, comparison of posterior methane profiles with measurements of $\mathrm{CH}_{4}$ vertical profiles from aircraft that were not used in the assimilation show very good agreement, giving further confidence in the estimated emissions over large scales, as well as the representation of the transport processes that maintain the free-tropospheric $\mathrm{CH}_{4}$ abundances. Large underestimates of $\mathrm{CH}_{4}$ abundance can sometimes occur at the lower levels of the aircraft profiles in regions where there are likely strong local/regional sources that cannot be resolved by the spatial resolution of the system, are underestimated by the prior emission estimates, and/or not "seen" by other sites. This implies that use of aircraft data could supply important constraints for future inversions.

We have also demonstrated the diagnostic value of globally and zonally integrated $\mathrm{CH}_{4}$ abundances. Comparison of observed and estimated global $\mathrm{CH}_{4}$ abundances allows determination of the relative importance of prior estimates and observational constraints to the solution. Likewise, comparison of observed and posterior $\mathrm{CH}_{4}$ mole fractions integrated over latitude zones indicates whether observational constraints are sufficient to capture observed temporal variability. Since the growth rate of globally and zonally integrated $\mathrm{CH}_{4}$ abundance directly reflects changes in emissions and sinks, comparison of observed and simulated integrated growth provides insight into whether the inter-annual variability of fluxes is accurately recovered. Indeed we have shown that CarbonTracker- $\mathrm{CH}_{4}$ is able to simulate the observed zonal average mole fractions and capture inter-annual variability in emissions quite well at high northern latitudes.
In contrast, CarbonTracker- $\mathrm{CH}_{4}$ is less successful in the tropics where it misses significant variability and is more influenced by prior flux estimates. This is expected given the limited number of tropical network sites and the short smoother EnKF time window.

CarbonTracker- $\mathrm{CH}_{4}$ posterior estimates of total fluxes at high northern latitudes are about $81 \pm 7 \mathrm{Tg} \mathrm{CH}_{4} \mathrm{yr}^{-1}$, about $12 \mathrm{Tg} \mathrm{CH}_{4} \mathrm{yr}^{-1}(13 \%)$ lower than prior estimates, a result that is consistent with other atmospheric inversions. Emissions from European wetlands are decreased by $30 \%$, as found by Bergamaschi et al. (2005); however, unlike their results, emissions from wetlands in boreal Eurasia are increased. Although CarbonTracker- $\mathrm{CH}_{4}$ does not estimate increases in emissions from high northern latitudes over the decade covered by the inversion, significant inter-annual variability is recovered. During the exceptionally warm and wet summer of 2007, estimated emissions were higher than the decadal average by $4.4 \pm 3.8 \mathrm{Tg} \mathrm{CH}_{4}$. It is encouraging that CarbonTracker- $\mathrm{CH}_{4}$ estimates for the Arctic agree reasonably well and within estimated uncertainties with the analysis of flux observations by McGuire et al. (2012), although they are somewhat lower $\left(16 \pm 5 \mathrm{Tg} \mathrm{CH}_{4} \mathrm{yr}^{-1}\right.$ compared to $25 \mathrm{Tg} \mathrm{CH}_{4} \mathrm{yr}^{-1}$ ).

CarbonTracker- $\mathrm{CH}_{4}$ estimates for temperate latitudes are slightly increased over prior estimates, but about $10 \mathrm{Tg} \mathrm{CH}_{4} \mathrm{yr}^{-1}$ is redistributed from Asia to North America, an amount that exceeds the posterior uncertainty estimate for North America $\left( \pm 3.5 \mathrm{Tg} \mathrm{CH}_{4} \mathrm{yr}^{-1}\right)$. We used time invariant prior flux estimates for 2000 through 2005 when the growth rate of global atmospheric $\mathrm{CH}_{4}$ was relatively small, so the assimilation does not estimate changes in natural or anthropogenic emissions. After 2006, when atmospheric $\mathrm{CH}_{4}$ began to increase again, CarbonTracker- $\mathrm{CH}_{4}$ allocates some of the emission increases to anthropogenic emissions at temperate latitudes, and some to tropical wetland emissions. The impact of increases in anthropogenic emissions from Asia implied by bottom up production statistics are not seen in the posterior flux estimates, but for temperate North America, the prior flux estimates are increased by about $4 \mathrm{Tg} \mathrm{CH}_{4} \mathrm{yr}^{-1}$ during winter when signals from much larger biogenic emissions are small, and amount that is larger than the estimated uncertainty of $3 \mathrm{TgCH}_{4} \mathrm{yr}^{-1}$. Examination of the residuals at North American observation sites suggests that increased $\mathrm{CH}_{4}$ emissions from gas and oil exploration may play a role.

The tropics are not currently well resolved by CarbonTracker- $\mathrm{CH}_{4}$ due to sparse observational coverage and a short smoother window. However, posterior uncertainties are slightly reduced from prior uncertainties and posterior emissions are about $18 \%$ higher than prior estimates. Most of this increase is allocated to tropical South America rather than being distributed over all tropical regions. Our estimates for tropical South America are about $32 \pm 4 \mathrm{Tg} \mathrm{CH}_{4} \mathrm{yr}^{-1}$, in good agreement with the analysis of Melack et al. (2004), who obtained $29 \mathrm{Tg} \mathrm{CH}_{4} \mathrm{yr}^{-1}$ for the Amazon Basin. 
As we have shown using CarbonTracker- $\mathrm{CH}_{4}$, even with the current sparse observational network it is possible to be able to draw conclusions about continental budgets of atmospheric $\mathrm{CH}_{4}$ and to track and attribute variability in relatively well-sampled regions. However, information about fluxes at policy relevant scales remains elusive without increased observational coverage. This is especially true in the tropics, where droughts and flooding may have significant impact on emissions.

Acknowledgements. This work, including the measurements that formed the basis for the study, were funded in part by NOAA's Atmospheric Chemistry, Carbon Cycle and Climate Program. The authors would like to thank M. Krol, W. Peters, S. Houweling, P. Bergamaschi and members of the TM5 Modeling Group for their support and helpful suggestions. The authors would also like to thank E. Chan for his helpful comments, and two anonymous reviewers for their suggestions.

Edited by: P. Jöckel

\section{References}

Bartlett, K. B. and Harriss, R. C.: Review and assessment of methane emissions from wetlands, Chemosphere, 26, 261-320, doi:10.1016/0045-6535(93)90427-7, 1993.

Beck, V., Chen, H., Gerbig, C., Bergamaschi, P., Bruhwiler, L., Houweling, S., Roeckmann, T., Kolle, O., Steinbach, J., Koch, T., Sapart, C. J., van der Veen, C., Frankenberg, C., Andreae, M. O., Artaxo, P., Longo, K. M., and Wofsy, S. C.: Methane airborne measurements and comparison to global models during BARCA, J. Geophys. Res., 117, D15310, doi:10.1029/2011JD017345, 2012.

Bergamaschi, P., Krol, M., Dentener, F., Vermeulen, A., Meinhardt, F., Graul, R., Ramonet, M., Peters, W., and Dlugokencky, E. J.: Inverse modelling of national and European $\mathrm{CH} 4$ emissions using the atmospheric zoom model TM5, Atmos. Chem. Phys., 5, 2431-2460, doi:10.5194/acp-5-2431-2005, 2005.

Bergamaschi, P., Frankenberg, C., Meirink, J. F., Krol, M., Dentener, F., Wagner, T., Platt, U., Kaplan, J. O., Korner, S., Heimann, M., Dlugokencky, E. J., and Goede, A.: Satellite chartography of atmospheric methane from SCIAMACHY on board ENVISAT: 2. Evaluation based on inverse model simulations, J. Geophys. Res., 112, D02304, doi:10.1029/2006JD007268, 2007.

Bergamaschi, P., Frankenberg, C., Meirink, J. F., Krol, M., Villani, M. G., Houweling, S., Dentener, F., Dlugokencky, E. J., Miller, J. G., Gatti, L. V., Engel, A., and Levin, I.: Inverse modeling of global and regional $\mathrm{CH}_{4}$ emissions using SCIAMACHY satellite retrievals, J. Geophys. Res., 114, D22301, doi:10.1029/2009JD012287, 2009.

Bergamaschi, P., Houweling, S., Segers, A., Krol, M., Frankenburg, C., Scheepmaker, R. A., Dlugokencky, E., Wofsy, S. C., Kort, E. A., Sweeney, C., Schuck, T., Brenninkmeijer, C., Chen, H., Beck, V., and Gerbig, C.: Atmospheric $\mathrm{CH}_{4}$ in the first decade of the 21 st century: Inverse modeling analysis using SCIAMACHY satellite retrievals and NOAA surface measurements, J. Geophys. Res., 118, 7350-7369, doi:10.1002/jgrd.50480, 2013.
Bloom, A. A., Palmer, P., Fraser, A., Reay, D., and Frankenberg, C.: Large-scale controls of methanogenesis inferred from methane and gravity spaceborne data, Science, 327, 322-325, doi:10.1126/science.1175176, 2010.

Bousquet, P., Ciais, P., Miller, J. B., Dlugokencky, E. J., Hauglustaine, D. A., Prigent, C., Van der Werf, G. R., Peylin, P., Brunke, E. G., Carouge, C., Langenfelds, R. L., Lathière, J., Papa, F., Ramonet, M., Schmidt, M., Steele, L. P., Tyler, S. C., and White, J.: Contribution of anthropogenic and natural sources to atmospheric methane variability, Nature, 443, 439443, doi:10.1038/nature05132, 2006.

Bousquet, P., Ringeval, B., Pison, I., Dlugokencky, E. J., Brunke, E.G., Carouge, C., Chevallier, F., Fortems-Cheiney, A., Frankenberg, C., Hauglustaine, D. A., Krummel, P. B., Langenfelds, R. L., Ramonet, M., Schmidt, M., Steele, L. P., Szopa, S., Yver, C., Viovy, N., and Ciais, P.: Source attribution of the changes in atmospheric methane for 2006-2008, Atmos. Chem. Phys., 11, 3689-3700, doi:10.5194/acp-11-3689-2011, 2011.

Bruhwiler, L. M. P., Michalak, A. M., Peters, W., Baker, D. F., and Tans, P.: An improved Kalman Smoother for atmospheric inversions, Atmos. Chem. Phys., 5, 2691-2702, doi:10.5194/acp-52691-2005, 2005.

Bruhwiler, L. M. P., Michalak, A. M., and Tans, P. P.: Spatial and temporal resolution of carbon flux estimates for 1983-2002, Biogeosciences, 8, 1309-1331, doi:10.5194/bg-8-1309-2011, 2011.

Chen, Y.-H. and Prinn, R. G.: Estimation of atmospheric methane emissions between 1996 and 2001 using a three-dimensional global chemical transport model, J. Geophys. Res., 111, D10307, doi:10.1029/2005JD006058, 2006.

Denning, A. S., Holzer, M., Gurney, K. R., Heimann, M., Law, R. M., Rayner, P. J., Fung, I. Y., Fan, S.-M., Taguchi, S., Friedlingstein, P., Balkanski, Y., Taylor, J., Maiss, M., and Levin, I.: Threedimensional transport and concentration of SF6 - A model intercomparison study (TransCom 2), Tellus B, 51, 266-297, 1999.

Denman, K. L., Brasseur, G., Chidthaisong, A., Ciais, P., Cox, P. M., Dickinson, R. E., Hauglustaine, D., Heinze, C., Holland, E., Jacob, D., Lohmann, U., Ramachandran, S., da Silva Dias, P. L., Wofsy, S. C., and Zhang, X.: Couplings Between Changes in the Climate System and Biogeochemistry, in: Climate Change 2007: The Physical Science Basis. Contribution of Working Group I to the Fourth Assessment Report of the Intergovernmental Panel on Climate Change, edited by: Solomon, S., Qin, D., Manning, M., Chen, Z., Marquis, M., Averyt, K. B., Tignor, M., and Miller, H. L., Cambridge University Press, Cambridge, UK and New York, NY, USA, 2007.

Dlugokencky, E. J., Steele, L. P., Lang, P. M., and Masarie, K. A.: The growth rate and distribution of atmospheric methane, J. Geophys. Res., 99, 17021-17043, doi:10.1029/94JD01245, 1994.

Dlugokencky, E. J., Houweling, S., Bruhwiler, L., Masarie, K. A., Lang, P. M., Miller, J. B., and Tans, P. P.: Atmospheric methane levels off: Temporary pause or a new steady-state?, Geophys. Res. Lett., 30, 1992, doi:10.1029/2003GL018126, 2003.

Dlugokencky, E. J., Myers, R. C., Lang, P. M., Masarie, K. A., Crotwell, A. M., Thoning, K. W., Hall, B. D., Elkins, J. W., and Steele, L. P.: Conversion of NOAA atmospheric dry air $\mathrm{CH}_{4}$ mole fractions to a gravimetrically prepared standard scale, J. Geophys. Res.-Atmos., 110, D18306, doi:10.1029/2005JD006035, 2005. 
Dlugokencky, E. J., Bruhwiler, L., White, J., Emmons, L., Novellie, P., Montka, S., Masarie, K., Lang, P., Crotwell, A., Miller, J., and Gatti, L.: Observational constraints on recent increases in the atmospheric $\mathrm{CH}_{4}$ burden, Geophys. Res. Lett., 36, L18803, doi:10.1029/2009GL039780, 2009.

Etheridge, D. M., Steele, L. P., Francey, R. J., and Langenfelds, R. L.: Atmospheric methane between 1000 A.D. and present: Evidence of anthropogenic emissions and climatic variability, J. Geophys. Res., 103, 15979-15993, doi:10.1029/98JD00923, 1998.

European Commission, Joint Research Centre (JRC)/Netherlands Environmental Assessment Agency (PBL). Emission Database for Global Atmospheric Research (EDGAR), release version 4.0, available at: http://edgar.jrc.ec.europa.eu (last access: May 2014), 2009.

Frolking, S., Talbot, J., Jones, M. C., Treat, C. C., Kauffman, J. B., Tuittila, E.-S., and Roulet, N.: Peatlands in the Earth's 21st century climate system, Environ. Rev., 19, 371-396, doi:10.1139/A11-014, 2011.

Giglio, L., van der Werf, G. R., Randerson, J. T., Collatz, G. J., and Kasibhatla, P.: Global estimation of burned area using MODIS active fire observations, Atmos. Chem. Phys., 6, 957974, doi:10.5194/acp-6-957-2006, 2006.

Gurney, K., Law, R., Rayner, P., and Denning, S.: “TransCom 3 Experimental Protocol," Department of Atmospheric Science, Colorado State University, paper no. 707, July 2000.

Harden, J. W., Koven, C., Ping, C., Hugelius, G., McGuire, A. D., Camill, P., Jorgenson, T., Kuhry, P., Michaelson, G. J., O’Donnell, J., Schuur, E. A., Tarnocai, C., Johnson, K., and Grosse, G.: Field information links permafrost carbon to physical vulnerabilities of thawing, Geophys. Res. Lett., 39, L15704, doi:10.1029/2012GL051958, 2012.

Hein, R., Crutzen, P. J., and Heimann, M.: An inverse modeling approach to investigate the global atmospheric methane cycle, Global. Biogeochem. Cy., 11, 43-76, 1997.

Hofmann, D. J., Butler, J. H., Dlugokencky, E. J., Elkins, J. W., Masarie, K., Montzka, S. A., and Tans, P.: The role of carbon dioxide in climate forcing from 1979-2004: Introduction of the Annual Greenhouse Gas Index, Tellus B, 58, 614-619, 2006.

Houtekamer, P. L. and Mitchell, H. L.: Data assimilation using an ensemble Kalman filter technique, Mon. Weather. Rev., 126, 796-811, 1998.

Houweling, S., Kaminski, T., Dentener, F., Lelieveld, J., and Heimann, M.: Inverse modeling of methane sources and sinks using the adjoint of a global transport model, J. Geophys. Res., 104, 26137-26160, doi:10.1029/1999JD900428, 1999.

Houweling, S., Krol, M., Bergamaschi, P., Frankenberg, C., Dlugokencky, E. J., Morino, I., Notholt, J., Sherlock, V., Wunch, D., Beck, V., Gerbig, C., Chen, H., Kort, E. A., Röckmann, T., and Aben, I.: A multi-year methane inversion using SCIAMACHY, accounting for systematic errors using TCCON measurements, Atmos. Chem. Phys., 14, 3991-4012, doi:10.5194/acp-14-39912014, 2014.

Kaminski, T., Rayner, P. J., Heimann, M., and Enting, I. G.: On aggregation errors in atmospheric transport inversions, J. Geophys. Res., 106, 4703-4715, 2001.

Kaplan, J. O.: Wetlands at the last glacial maximum: Distribution and methane emissions, Geophys. Res. Lett., 29, 1079, doi:10.1029/2001GL013366, 2002.
Karion, A., Sweeney, C., Pétron, G., Frost, G., Hardesty, R. M., Kofler, J., Miller, B. R., Newberger, T., Wolter, S., Banta, R., Brewer, A., Dlugokencky, E., Lang, P., Montzka, S. A., Schnell, R., Tans, P., Trainer, M., Zamora, R., and Conley, S.: Methane emissions estimate from airborne measurements over a western United States natural gas field, Geophys. Res. Lett., 40, 43934397, doi:10.1002/grl.50811, 2013.

Kirschke, S., Bousquet, P., Ciais, P., Saunois, M., Canadell, J. G., Dlugokencky, E. J., Bergamaschi, P., Bergmann, D., Blake, D. R., Bruhwiler, L., Cameron-Smith, P., Castaldi, S., Chevallier, F., Feng, L., Fraser, A., Heimann, M., Hodson, E. L., Houweling, S., Josse, B., Fraser, P. J ., Krummel, P. B., Lamarque, J.F., Langenfelds, R. L., Le Quéré, C., Naik, V., O’Doherty, S., Palmer, P. I., Pison, I., Plummer, D., Poulter, B., Prinn, R. G., Rigby, M., Ringeval, B., Santini, M., Schmidt, M., Shindell, D. T., Simpson, I. J., Spahni, R., Steele, L. P., Strode, S. A., Sudo, K., Szopa, S., van der Werf, G.R., Voulgarakis, A., van Weele, M., Weiss, R. F., Williams, J. E., and Zeng, G.: Three decades of global methane sources and sinks, Nat. Geosci., 6, 813-823, doi:10.1038/ngeo1955, 2013.

Krol, M., van Leeuwen, P. J., and Lelieveld, J.: Global OH trend inferred from methylchloroform measurements, J. Geophys. Res., 103, 10697-10711, doi:10.1029/98JD00459, 1998.

Krol, M., Houweling, S., Bregman, B., van den Broek, M., Segers, A., van Velthoven, P., Peters, W., Dentener, F., and Bergamaschi, P.: The two-way nested global chemistry-transport zoom model TM5: algorithm and applications, Atmos. Chem. Phys., 5, 417432, doi:10.5194/acp-5-417-2005, 2005.

Lambert, G. and Schmidt, S.: Re-evaluation of the oceanic flux of methane: uncertainties and long term variations, Chemosphere, 26, 579-590, 1993.

Loulergue, L., Schilt, A., Spahni, R., Masson-Delmotte, V., Blunier, T., Lemieux, B., Barnola, J.-M., Raynaud, D., Stocker, T. F., and Chappellaz, J.: Orbital and millennial-scale features of atmospheric $\mathrm{CH}_{4}$ over the past 800,000 years, Nature, 453, 383386, doi:10.1038/nature06950, 2008.

Masarie, K. A. and Tans, P. P.: Extension and integration of atmospheric carbon dioxide data into a globally consistent measurement record, J. Geophys. Res.-Atmos., 100, 11593-11610, 1995.

Matthews, E.: Global Data Bases on Distribution, Characteristics and Methane Emission of Natural Wetlands: Documentation of Archived Data Tape, NASA TM-4153, National Aeronautics and Space Administration, 1989.

Matthews, E., Fung, I., and Lerner, J.: Methane emission from rice cultivation: Geographic and seasonal distribution of cultivated areas and emissions, Global Biogeochem. Cy., 5, 3-24, 1991.

McGuire, A. D., Christensen, T. R., Hayes, D., Heroult, A., Euskirchen, E., Kimball, J. S., Koven, C., Lafleur, P., Miller, P. A., Oechel, W., Peylin, P., Williams, M., and Yi, Y.: An assessment of the carbon balance of Arctic tundra: comparisons among observations, process models, and atmospheric inversions, Biogeosciences, 9, 3185-3204, doi:10.5194/bg-9-3185-2012, 2012.

Melack, J. M., Hess, L. L., Gastil, M., Forsberg, B. R., Hamilton, S. K., Lima, I. B. T., and Novo, E. M. L. M.: Regionalization of methane emissions in the Amazon Basin with microwave remote sensing, Glob. Change Biol., 10, 530-544, doi:10.1111/j.13652486.2004.00763.x, 2004.

Melton, J. R., Wania, R., Hodson, E. L., Poulter, B., Ringeval, B., Spahni, R., Bohn, T., Avis, C. A., Beerling, D. J., Chen, G., 
Eliseev, A. V., Denisov, S. N., Hopcroft, P. O., Lettenmaier, D. P., Riley, W. J., Singarayer, J. S., Subin, Z. M., Tian, H., Zürcher, S., Brovkin, V., van Bodegom, P. M., Kleinen, T., Yu, Z. C., and Kaplan, J. O.: Present state of global wetland extent and wetland methane modelling: conclusions from a model intercomparison project (WETCHIMP), Biogeosciences, 10, 753788, doi:10.5194/bg-10-753-2013, 2013.

Miller, J. B., Mack, K. A., Dissly, R., White, J. W. C., Dlugokencky, E. J., and Tans, P. P.: Development of analytical methods and measurements of $13 \mathrm{C} / 12 \mathrm{C}$ in atmospheric $\mathrm{CH}_{4}$ from the NOAA Climate Monitoring and Diagnostics Laboratory Global Air Sampling Network, J. Geophys. Res.-Atmos., 107, 4178, doi:10.1029/2001JD000630, 2002.

Miller, J. B., Gatti, L. V., D’Amelio, M. T. S., Crotwell, A., Dlugokencky, E., Bakwin, P. S., Artaxo, P., and Tans, P.: Airborne sampling reveals large methane enhancement over the Amazon basin, Geophys. Res. Lett., 34, L10809, doi:10.1029/2006GL029213, 2007.

Miller, S. M., Wofsy, S. C., Michalak, A. M., Kort, E. A., Andrews, A. E., Biraud, S. C., Dlugokencky, E. J., Eluszkiewicz, J., Fischer, M. L., Janssens-Maenhout, G., Miller, B. R., Miller, J. B., Montzka, S. A., Nehrkorn, T., and Sweeney, C.: Anthropogenic emissions of methane in the United States, P. Natl. Acad. Sci., 110, 20018-20022, doi:10.1073/pnas.1314392110, 2013.

Mikaloff-Fletcher, S. E., Tans, P. P., Bruhwiler, L. M., Miller, J. B., and Heimann, M.: $\mathrm{CH}_{4}$ sources estimated from atmospheric observations of $\mathrm{CH}_{4}$ and its ${ }^{13} \mathrm{C} /{ }^{12} \mathrm{C}$ isotopic ratios: 1 . Inverse modeling of source processes, Global Biogeochem. Cy., 18, GB4004, doi:10.1029/2004GB002223, 2004a.

Mikaloff-Fletcher, S. E., Tans, P. P., Bruhwiler, L. M., Miller, J. B., and Heimann, M.: $\mathrm{CH}_{4}$ sources estimated from atmospheric observations of $\mathrm{CH}_{4}$ and its ${ }^{13} \mathrm{C} /{ }^{12} \mathrm{C}$ isotopic ratios: 2. Inverse modeling of $\mathrm{CH}_{4}$ fluxes from geographical regions, Global Biogeochem. Cy., 18, GB4005, doi:10.1029/2004GB002224, 2004b.

Montzka, S. A., Krol, M., Dlugokencky, E., Hall, B., Jockel, P., Lelieveld, J.: Small Interannual Variability of Global Atmospheric Hydroxyl, Science, 331, 6013, doi:10.1126/science.1197640, 2011.

Myhre, G., Shindell, D., Bréon, F.-M., Collins, W., Fuglestvedt, J., Huang, J., Koch, D., Lamarque, J.-F., Lee, D., Mendoza, B., Nakajima, T., Robock, A., Stephens, G., Takemura, T., and Zhang, H.: Anthropogenic and Natural Radiative Forcing, in: =Climate Change 2013: The Physical Science Basis. Contribution of Working Group I to the Fifth Assessment Report of the Intergovernmental Panel on Climate Change, edited by: Stocker, T. F., Qin, D., Plattner, G.-K., Tignor, M., Allen, S. K., Boschung, J., Nauels, A., Xia, Y., Bex, V., and Midgley, P. M., Cambridge University Press, Cambridge, United Kingdom and New York, NY, USA, 2013.

Peters, W., Krol, M. C., Dlugokencky, E. J., Dentener, F. J., Bergamaschi, P., Dutton, G., Velthoven, P. V., Miller, J. B., Bruhwiler, L., and Tans, P. P.: Toward regional-scale modeling using the two-way nested global model TM5: Characterization of transport using $\mathrm{SF}_{6}$, J. Geophys. Res., 109, D19314, doi:10.1029/2004JD005020, 2004.

Peters, W., Miller, J. B., Whitaker, J., Denning, A. S., Hirsch, A., Krol, M. C., Zupanski, D., Bruhwiler, L., and Tans, P. P.: An ensemble data assimilation system to estimate $\mathrm{CO}_{2}$ surface fluxes from atmospheric trace gas observations, J. Geophys. Res., 110, D24304, doi:10.1029/2005JD006157, 2005.

Peters, W., Jacobson, A. R., Sweeney, C., Andrews, A., Conway, T. J., Masarie, K. A., Miller, J. B., Bruhwiler, L., Petron, G., Hirsch, A., Worthy, D., van der Werf, G., Randerson, J. T., Wennberg, P., Krol, M., and Tans, P. P.: An atmospheric perspective on North American carbon dioxide exchange: CarbonTracker, P. Natl. Acad. Sci. USA, 104, 1892518930, doi:10.1073/pnas.0708986104, 2007.

Pétron, G., Frost, G., Miller, B. R., Hirsch, A. I., Montzka, S. A., Karion, A., Trainer, M., Sweeney, C., Andrews, A. E., Miller, L., Kofler, J., Bar-Ilan, A., Dlugokencky, E. J., Patrick, L., Moore Jr., C. T., Ryerson, T. B., Siso, C., Kolodzey, W., Lang, P. M., Conway, T., Novelli, P., Masarie, K., Hall, B., Guenther, D., Kitzis, D., Miller, J., Welsh, D., Wolfe, D., Neff, W., and Tans, P.: Hydrocarbon emissions characterization in the Colorado Front Range: A pilot study, J. Geophys. Res., 117, D04304, doi:10.1029/2011JD016360, 2012.

Rayner, P. J., Scholze, M., Knorr, W., Kaminski, T., Giering, R., and Widmann, H.: Two decades of terrestrial carbon fluxes from a carbon cycle data assimilation system (CCDAS), Global Biogeochem. Cy., 19, GB2026, doi:10.1029/2004GB002254, 2005.

Rhee, T. S., Kettle, A. J., and Andreae, M. O.: Methane and nitrous oxide emissions from the ocean: A reassessment using basin-wide observations in the Atlantic, J. Geophys. Res., 114, D12304, doi:10.1029/2008JD011662, 2009.

Ridgwell, A. J., Marshall, S. J., and Gregson, K.: Consumption of atmospheric methane by soils: A process-based model, Global Biogeochem. Cy., 13, 59-70, doi:10.1029/1998GB900004, 1999.

Rigby, M., Prinn, R. G., Fraser, P. J., Simmonds, P. G., Langenfelds, R. L., Huang, J., Cunnold, D. M., Steele, L. P., Krummel, P. B., Weiss, R. F., O’Doherty, S., Salameh, P. K., Wang, H. J., Harth, C. M., Muhle, J., and Porter, L. W.: Renewed growth of atmospheric methane, Geophys. Res. Lett., 35, L22805, doi:10.1029/2008g1036037, 2008.

Sanderson, M. G.: Biomass of termites and their emissions of methane and carbon dioxide: A global database, Global Biogeochem. Cy., 10, 543-557, doi:10.1029/96GB01893, 1996.

Schaefer, K., Zhang, T., Bruhwiler, L., and Barrett, A. P.: Strength and timing of the permafrost carbon feedback, Tellus B, 63, 165180, doi:10.1111/j.1600-0889.2011.00527.x, 2011.

Schuur, E. A., Abbott, B., and the Permafrost Carbon Network: High Risk of Permafrost Thaw, Nature, 480, 32-33, 2011.

Shakhova, N., Semiletov, I., Salyuk, A., Yusupov, V., Kosmach, D., and Gustafsson, O.: Extensive Methane Venting to the Atmosphere from Sediments of the East Siberian Arctic Shelf, Science, 327, 1246-1250, doi:10.1126/science.1182221, 2010.

Shakhova, N., Semilitov, I., Leifer, I., Sergienko, V., Salyuk, A., Kosmach, D., Chernykh, D., Stubbs, C., Nicolsky, D., Tumskoy, V., and Gustafsson, O.: Ebullition and storm-induced methane release from the East Siberian Arctic Shelf, Nat. Geosci., 7, 64 70, doi:10.1038/ngeo2007, 2013.

Spahni, R., Wania, R., Neef, L., van Weele, M., Pison, I., Bousquet, P., Frankenberg, C., Foster, P. N., Joos, F., Prentice, I. C., and van Velthoven, P.: Constraining global methane emissions and uptake by ecosystems, Biogeosciences, 8, 1643-1665, doi:10.5194/bg8-1643-2011, 2011. 
Stroeve, J., Serreze, M., Drobot, S., Gearheard, S., Holland, M., Maslanik, J., Meier, W., and Scambos, T.: Arctic Sea Ice Extent Plummets in 2007, Eos, Transactions, American Geophysical Union, 89, 13-14, doi:10.1029/2008EO020001, 2008.

Tarnocai, C., Canadell, J. G., Schuur, E. A. G., Kuhry, P., Mazhitova, G., and Zimov, S.: Soil organic carbon pools in the northern circumpolar permafrost region, Global Biogeochem. Cy., 23, GB2023, doi:10.1029/2008GB003327, 2009.

Walter, A. K., Smith, L. C., and Chapin III, F. S.: Methane bubbling from northern lakes: present and future contributions to the global methane budget, Philos. T. R. Soc. A., 365, 1657-1676, doi:10.1098/rsta.2007.2036, 2007.

van der Werf, G. R., Randerson, J. T., Giglio, L., Collatz, G. J., Kasibhatla, P. S., and Arellano Jr., A. F.: Interannual variability in global biomass burning emissions from 1997 to 2004, Atmos. Chem. Phys., 6, 3423-3441, doi:10.5194/acp-6-3423-2006, 2006.
Walter, A. K., Anthony, P., Grosse, G., and Chanton, J.: Geologic methane seeps along boundaries of Arctic permafrost thaw and melting glaciers, Nat. Geosci., 5, 419-426, doi:10.1038/NGEO1480, 2012.

Whitaker, J. S. and Hamill, T. M.: Ensemble Data Assimilation without Perturbed Observations, Mon. Weather Rev., 130, 1913-1924, doi:10.1175/15200493(2002)130<1913:EDAWPO>2.0.CO;2, 2002.

Yan, X., Akiyama, H., Yagi, K., and Akimoto, H.: Global estimations of the inventory and mitigation potential of methane emissions from rice cultivation conducted using the 2006 Intergovernmental Panel on Climate Change Guidelines, Global Biogeochem. Cy., 23, GB2002, doi:10.1029/2008GB003299, 2009. 